\title{
CÁLCIO NA PRODUÇÃO DE MATÉRIA SECA E NA COMPOSIÇÃO MINERAL DO MILHETO FORRAGEIRO \\ (Pennisetum americanum (L.) K. Schum)
}

\author{
ALDI FERNANDES DE SOUZA FRANÇA \\ Zootecnista - MS
}

Orientador: Prof. Dr. HENRIQUE PAULO HAAG

Tese apresentada à Escola Superior de Agricultura "Luiz de Queiroz", da Universidade de São Paulo, para obtenção do título de Doutor em Agronomia. Área de Concentração: Solos e Nutrição de Plantas.

\footnotetext{
PIRACICABA

Estado de São Paulo - Brasil Junho = 1987
} 
Aos meus pais,

MARIA e LUIZ FRANÇA

DEDICO.
A minha esposa,

ELENI MARIA,

pelo apoio e incentivo

$e$ aos nossos bilhos.

LUIZ CLAUDIO

ANDERSON ALDI $e$

DANIELA CRISTINA

OFEREÇO. 


\section{AGRADECIMENTOS}

Ao Prof. Dr. Henrique paulo Haag pela indispensável orientação, pela experiência transmitida e acima de tudo pelo censo humano e de amizade.

Aos Profs. Dr. Antonio Roque Dechen e Quirino Augusto C. Car mello pela orientação na condução das análises e pelas facilidades concedidas para utilização do laboratório.

Ao Prof. Quirino Augusto C. Carmello pela realização das anālises estatísticas.

Aos Colegas Romão da Cunha Nunes, Delcione Silveira e Marilu Zaldiva Diniz, pelo incentivo e apoio durante a realização do curso.

Aos funcionários do laboratório de nutrição mineral de plan tas Lúcia Helena P. Fortes, Lourdes Aparecida D. Gonzales, Mirtes Ventura Cesso e Claudemir Fornagio pela boa vontade demonstrada na realização das análises químicas.

A Universidade Federal de Goiās, atravês uo Departamento de Zootecnia, pela oportunidade concedida para a rea lização do curso.

Ao Conselho Nacional de Pesquisas pela concessão da bolsa de estudos. 
iv.

SUMARIO

Página

LISTA DE TABELAS $\ldots \ldots \ldots \ldots \ldots \ldots \ldots \ldots \ldots \ldots \ldots \ldots \ldots \ldots \ldots$ v.

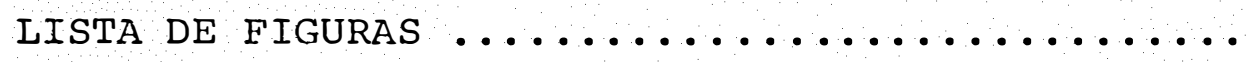
viii

RESUMO $\ldots \ldots \ldots \ldots \ldots \ldots \ldots \ldots \ldots \ldots \ldots \ldots \ldots \ldots \ldots \ldots \ldots \ldots \ldots \ldots \ldots \ldots \ldots$ xii

SUMMARY xiii

1. INTRODUÇÃ

01

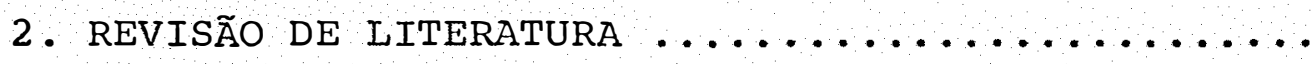

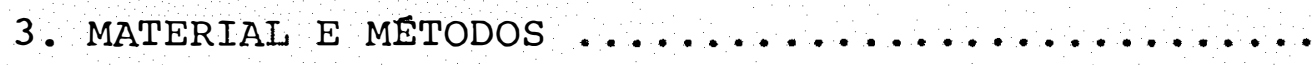

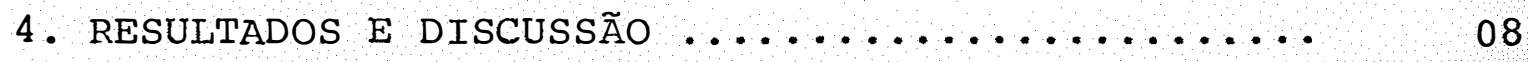

4.1. Produção de matéria seca ...............

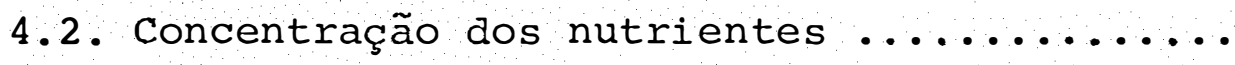

4.2 .1 . Nitrogênio $\ldots \ldots \ldots \ldots \ldots \ldots \ldots \ldots \ldots \ldots \ldots \ldots \ldots \ldots$

4.2 .2 . Fósforo $\ldots \ldots \ldots \ldots \ldots \ldots \ldots \ldots \ldots \ldots \ldots \ldots \ldots \ldots$

15

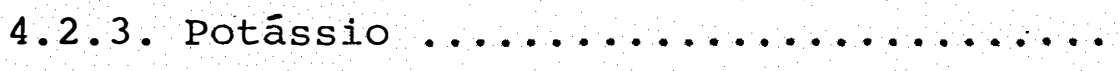

20

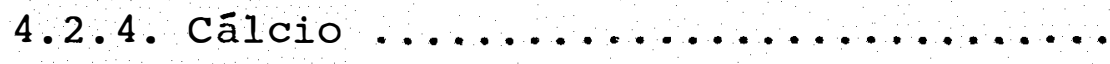

23

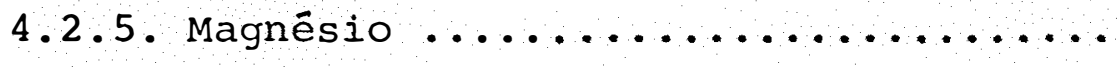

27

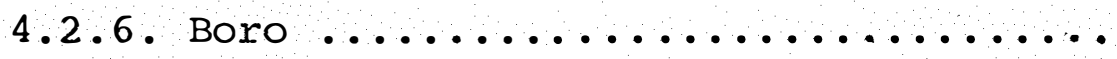

31

$4.2 .7 . \mathrm{Zinco} \ldots \ldots \ldots \ldots \ldots \ldots \ldots \ldots \ldots \ldots \ldots \ldots \ldots \ldots \ldots \ldots \ldots$

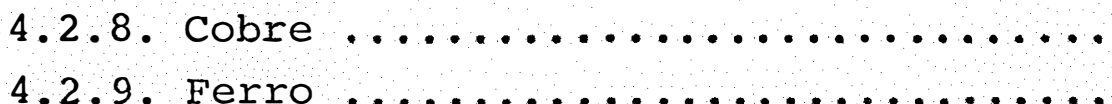

4.2 .10 . Manganês $\ldots \ldots \ldots \ldots \ldots \ldots \ldots$

5. CONCLUSÕES $\ldots \ldots \ldots \ldots \ldots \ldots \ldots \ldots \ldots \ldots \ldots \ldots \ldots \ldots \ldots \ldots \ldots \ldots \ldots \ldots$ 


\section{LISTA DE TABELAS}

TABELA NO

pāgina

01 Produção total de matēria seca do milheto forrageiro, obtida em função dos tratamen tos aplicados. Média de quatro repetições, com três plantas/vaso ...........

02 Valores de $\mathrm{N}$ (\%), determinados nas folhas adjacentes, espigas e colmos do milheto forrageiro, em função dos diferentes níveis de cálcio aplicados. Média de quatro repetições com três plantas/vaso .......

Valores de (\%), determinados nas folhas adjacentes, espigas e coluos do milheto forrageiro, em função dos diferentes niveis de cálcio aplicados. Média de quatro repetições com três plantas/vaso .......

04 Valores de $\mathrm{K}$ (\%), determinados nas folhas adjacentes, espigas e colmos do milheto forrageiro, em função dos diferentes niveis de cálcio aplicados. Média de quatro repetições com três plantas/vaso. .......

05 Valores de $\mathrm{Ca}(\%)$, determinados nas foIhas adjacentes, espigas e colmos de miIheto forrageito, em função dos diferentes níveis de cálcio aplicados. Média de quatro repetições com três plantas / vaso ........................ 
Valores de Mg (\%), determinados nas folhas adjacentes, espigas e colmos do milheto forrageiro, em função dos diferentes níveis de cálcio aplicados. Média de quatro repetições com três plantas/vaso.

07 Valores de B ( $\mu g)$, determinados nas folhas não adjacentes, espigas e colmos de milheto forrageiro, em função dos diferen tes niveis de cálcio aplicados. Média de quatro repetições, com três plantas por

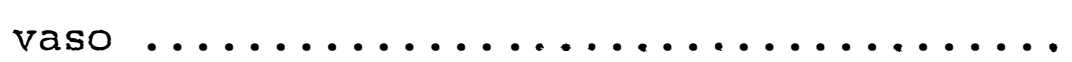

08 Valores de $\mathrm{Zn}(\mu \mathrm{g})$, determinados nas folhas adjacentes, folhas não adjacentes, es pigas e colmos de milheto forrageiro, em função dos diferentes nîveis de cálcio aplicados. Média de quatro repetições, com

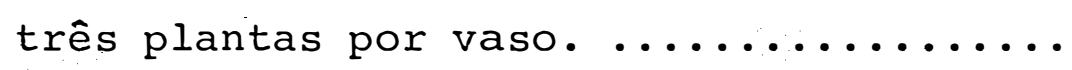

09 Valores de $\mathrm{Cu}(\mu \mathrm{g})$, determinados nas folhas adjacentes, folhas não adjacentes, espigas e colmos de milheto forrageiro, em função dos diferentes níveis de cálcio aplicados. Média de quatro repetições, com

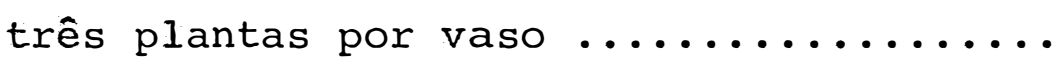

10 Valores de $\mathrm{Fe}(\mu \mathrm{g})$, determinados nas folhas adjacentes, folhas não adjacentes, es pigas e colmos de milheto forrageiro, em função dos diferentes níveis de cálcio aplicados. Média de quatro repetições com

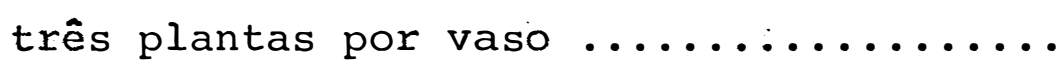


vii.

TABELA NO

pāgina

11 Valores de $M n(\mu g)$, determinados nas folhas adjacientes, folhas não adjacentes, es pigas e colmos de milheto forrageiro, em função dos diferentes níveis de cálcio aplicados. Média de quatro repetições com

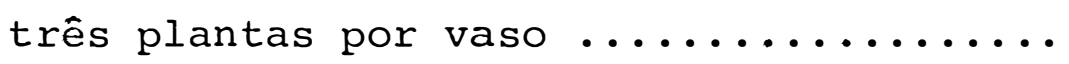


viii.

\section{LISTA DE FIGURAS}

FIGURA NQ

pāgina

01 Produção de matēria seca (g), obtida dos diferentes níveis de cálcio aplicados ao milheto forrageiro ...............

02 Teores de nitrogênio (\%), determinados nas diferentes partes do milheto forrageiro, em função dos níveis de cálcio aplicados.

03 Teores de fôsforo (\%), determinados nas diferentes partes do milheto forrageiro, em função dos níveis de cálcio aplicados.

04 Teores de potássio (\%), determinados nas diferentes partes do milheto forrageiro, em função dos níveis de cálcio aplicados.

Teores de cálcio (\%), determinados nas diferentes partes do milheto forrageiro, em função dos níveis de cálcio aplicados.

06

Teores de magnésio (\%), determinados nas diferentes partes do milheto forrageiro, em função dos níveis de cálcio aplicados.

Teores de B $(\mu \mathrm{g})$ determinados nas diferen tes partes do milheto forrageiro em função dos níveis de cálcio aplicados ...... 
08 Teores de zinco ( $\mu \mathrm{g})$ determinados nas diferentes partes do milheto forrageiro, em função dos níveis de cálcio aplicados ....

09 Teores de cobre (pg) determinados nas diferentes partes do milheto forrageiro, em função doss níveis de cálcio aplicados ...

10 Teores de ferro ( $\mu g$ ) determinados nas diferentes partes do milheto forrageiro, em função dos níveis de cálcio aplicados ....

11 Teores de manganês $(\mu g)$ determinados nas diferentes partes do milheto forrageiro, em função dos nívels de cālcio aplicados. 
CÁLCIO NA PRODUCÃO DE MATÉRIA SECA E NA COMPOSICÃO MINERAL DO MILHETO FORRAGEIRO (PENNISETUM AMERICANUM (L.) Ka SCHUM.)

Autor: ALDI FERNANDES DE SOUZA FRANÇA

Orientador: Prof. Dr. HENRIQUE PAULO HAAG

\section{RESUMO}

Para pesquisar o efeito de diferentes niveis de cálcio, sobre a produção de matéria seca e a composição mineral do milheto forrageiro, foi conduzido um experimento em ca sa de vegetação, durante trinta e oito dias. Foram aplicados os tratamentos: $0,50,100,150,200,250$ e 300 ppm de cálcío na solução nutritiva. As plantas foram divididas em folhas adjacentes, folhas não adjacentes, espigas e colmo, que foram analisadas para $\mathrm{N}, \mathrm{P}, \mathrm{K}, \mathrm{Ca}, \mathrm{Mg}, \mathrm{B}, \mathrm{Cu}, \mathrm{Fe}, \mathrm{Mn}$ e $\mathrm{Zn}$. As pro duções de matéria seca (g), obtidas em função da aplicação dos diferentes níveis de cálcio foram: $0=35,5 ; 50=54,6$; $100=$ $63,0,150=65,3 ; 200=69,6 ; 250=49,4$ e $300 \mathrm{ppm}=55,9$ g. A concentração dos macronutrientes nas diferentes partes da planta, apresentaram a seguinte variação: N - 0,57\% nos colmos, até $2,28 \%$ nas espigas, $\mathrm{P}-0,05 \%$ nos colmos, até $0,31 \%$ nas folhas adjacentes; $K-0,83 \%$ nas espigas, até $3,23 \%$ nas folhas adją centes; $\mathrm{Ca}-0,04 \%$ nos colmos, até 1,08\% nas follhas não adjacentes; Mg - 0,16\% nas espigas até $0,59 \%$ nas folhas não adjacentes; enquanto o, acúmulo dos micronutrientes foi da seguinte ordem: $B-157,7 \mu \mathrm{g}$ nas folhas adjacentes até $1.305,5 \mu \mathrm{g}$ 
nas folhas não adjacentes; $\mathrm{Zn}-152,3 \mu \mathrm{g}$ nos colmos, até $1.254,6 \mu \mathrm{g}$ nas espigas; $\mathrm{Cu}$ - 10,3 $\mu \mathrm{g}$ nas folhas adjacentes, até 118,5 $\mathrm{kg}$ nas espigas; $\mathrm{Fe}-344,8 \mu \mathrm{g}$ nas folhas, até $4.344,1 \mu \mathrm{g}$ nos colmos, até $1.749,9 \mu \mathrm{g}$ nas folhas não adjacentes e $\mathrm{Mn}-120,5 \mu \mathrm{g}$ nos colmos, até $1.749,9 \mu \mathrm{g}$ nas folhas não adjacentes. 0 autor concluiu:

1) A aplicação dos diferentes níveis de cálcio na produção de matéria seca obedece a uma equação do 29 grau com uma produção máxima aos 200 ppm de cálcio na solução nutritiva;

2) os níveis de cálcio aplicados reduziu a concentração de $\mathrm{N}, \mathrm{P}, \mathrm{K}, \mathrm{Ca}, \mathrm{Mg}, \mathrm{Zn}, \mathrm{Cu}, \mathrm{Fe}$ e $\mathrm{Mn}$;

3) os níveis de cālcio aplicados não reduziram a absorção de boro;

4) os níveis de cálcio aplicados nas soluções nutritivas não afetaram os requerimentos mínimos dos elementos para a nutrição dos bovinos. 
EFFECT OF CALCIUM ON DRY MATTER PRODUCTION AND MINERAL COMPOSITION OF MILLETS (PENNISETUM AMERICANUM (L.) K. SCHUM.)

Author: ALDI FERNANDES DE SOUZA FRANÇA

Adviser: Prof. Dr. HENRIQUE PAULO HAAG

\section{SUMMARY}

An experiment was conducted under greenhouse conditions to check the effect of different levels of calcium on the production of dry matter, and on the mineral composition of millet during 38 days. The following treatments were applied: $0,50,100,150,200,250$ and $300 \mathrm{ppm}$ of calcium in the nutrient solution. The plants were harvested in to young leaves, old leaves, ears, and stalks, which were analyzed for $\mathrm{N}, \mathrm{P}, \mathrm{K}, \mathrm{Ca}, \mathrm{Mg}, \mathrm{B} . \mathrm{Cu}, \mathrm{Fe}, \mathrm{Mn}, \mathrm{Zn}$. The out put dry matter (gr.), obtained by applying different levels of calcium were: $0=35.5,50=54.6,100=63.0,150=65.3,200=69,6$, $250=49.4$, and $300 \mathrm{ppm}=55.9 \mathrm{gr}$. The concentration of nutrients in different parts of the plant presented the following variation: $\mathrm{N}-0.57 \%$ in the stalks, up to $2.28 \%$ in the ears, $\mathrm{P}-0.05 \%$ in the stalks, upt to $0.31 \%$ in young leaves, $\mathrm{K}-0.83 \%$ in the ears, up to 3.23 in young leaves, $\mathrm{Ca}-0.04 \%$ in the stalks, up to $1.08 \%$ in older leaves, $\mathrm{Mg}$ $0.16 \%$ in ears, up to $0.59 \%$ in older leaves, B $-152,7 \mu \mathrm{g}$ in ears, $\mathrm{Cu}-10.3 \mu \mathrm{g}$ in young leaves, up to $118,5 \mu \mathrm{g}$ in ears, Fe $-344,8 \mu \mathrm{g}$ in young leaves, up to $4,344.1 \mu \mathrm{g}$ in older 
leaves, and $\mathrm{Mn}$ - $120.5 \mu \mathrm{g}$ in stalks, up to $1,749 \mathrm{\mu g}$ in older leaves. The author concluded:

1) The dry matter production obcy in equation of $2 \%$ degree, with a maximum production with $200 \mathrm{ppm}$ of $\mathrm{Ca}$ in the nutrient solution;

2) the calcium levels reduced the concentration of $N, P, K$, $\mathrm{Ca}, \mathrm{Mg}, \mathrm{Zn}, \mathrm{Cu}, \mathrm{Fe}$ and $\mathrm{Mn}$;

3) the Ca levels did not affect the absorption of boron;

4) the Ca levels in the nutrient solution did not affect the minimum requirements of the elements for cattle nutrition. 


\section{INTRODUGÃO}

o cálcio é um elemento essencial para o desenvolvimento das plantas, tendo participação em vārias reações fisiológicas e metabólicas.

Entretanto, as plantas diferem marcadamente em sua habilidade de absorção e metabolização do cálcio. Estas diferenças são, via de regra, manifestadas pela adaptação de certas plantas às condições específicas do solo e à predominân cia de certas espécies sobre outras segundo BRUSTROM (1968). No solo, existe aproximadamente 1\% de cálcio total, quantidade que varia em função do clima e do tipo de solo.

Para os solos da Amazônia, VIEIRA (1975), afị ma que os perfis dos solos em seu horizonte $A_{1}$, apresentam teores de cálcio variando de 0,10 a 28,0 meq $/ 100 \mathrm{~g}$, para Terra Roxa Estruturada e Areia Quartzosa, respectivamente. Segundo MALAVOLTA et alii (1976), os teores de cálcio na camada arável dos solos do Brasil, apresentam uma variação de 0,18 a $22,10 \mathrm{meq} / 100 \mathrm{~g}$. GONZALES-ERICO (1976) determinou a concentra ção média de 1,2 meq/loade cálcio solúvel para Latossolo Vermelho da região do Brasil Central. Para os solos das regiões 
úmidas, o teor de cálcio pode estar relacionado com altas precipitações. Solos com elevado teor de matéria orgânica, em geral apresentam os mais altos teores de Ca total. Solos com elevado teor de argila também apresentam altos teores, enquanto os solos arenosos apresentam teores mais baixos. Tal fato se explica pela maior CTC dos solos orgânicos e argilosos segundo MASCARENHAS (1977). MALAVOLTA et alii (1979) estimaram que o deficit anual de cálcio para os solos da América Latina é de aproximadamente de um milhão de toneladas de CaO, como nutriente, excluida a quantidade necessária como corretivo da acidez do solo. LOPES (1983) determinou o teor de cálcio trocável em diversas amostras de solos sob vegetação de cerrado, as quais variaram de 0,04 a $6,8 \mathrm{meq} / 100 \mathrm{~g}$, sen do a média de 0,25 meq/100g. Segundo o autor, uma porcentagem das amostras analisadas apresentavam uma considerável deficiência de cálcio para a maioria das culturas.

o milheto, apresenta a capacidade de adaptação a uma grande variedade de solos, não tolerando os enchar cados, preferindo os argilosos e conduzindo-se bem em solos de baixa fertilidade, muito ácidos, os quais são extremamente pobres para a cultura do sorgo e do milho (SMITH \& CLARK, 1968).

Do ponto de vista da nutrição animal, apresenta proteína de melhor qualidade, em relação à maioria dos cereais, variando entre 8 a $20 \%$ (BURTON et aIi1, 1972; BAILEY et alii, 1979). o milheto contém significante quantidade dos 
minerais necessários para a boa nutrição animal segundo CASEY \& LORENS (1977).

Considerando-se o alto potencial de produção do milheto forrageiro, o elevado valor nutritivo, aliados à capacidade de adaptação aos solos ácidos e de baixa fertilidą de, fazem do milheto uma espécie muito promissora, como mais uma alternativa de suplementação volumosa para o período crítico das secas.

Os objetivos foram: 19) estudar a influência de diferentes níveis de cálcio no substrato na produção de matéria seca; 29) a composição mineral de N, P, K, Ca, Mg, S, Ca, $\mathrm{Fe}, \mathrm{Mn}$ e $\mathrm{zn}$ do milheto forrageiro e 39) sua influência nos níveis analiticos para os requerimentos bovinos. 


\section{REVISÃO DE LITERATURA}

FRANÇA et alii. (1987) através de um trabalho conduzido sob condições controladas, utilizando soluções nutritivas completas e com omissões de nutrientes, determina ram a composição mineral do milheto forrageiro. As concentrações de N, P, Ca e Mg determinadas para as folhas adjacen tes, folhas "não adjacentes" espigas e colmos foram assim dis tribuídas: $\mathrm{N}=3,21 \%, 2,66 \%, 2,51 \%$ e 1,87\%; $\mathrm{P}=0,38 \%, 0,15 \%$, $0,58 \%$ e $0,14 \% ; \mathrm{Ca}=0,52 \%, 0,92 \%, 0,27 \%$ e $0,57 \%$ e $\mathrm{Mg}=0,48 \%$, $0,80 \%, 0,35 \%$ e $0,79 \%$, respectivamente.

Não se encontra na literatura trabalhos referentes à nutrição mineral do milheto (Pennisetum americanum). 


\section{MATERIAL E MÉTODOS}

O milheto é uma espécie extremamente variável, anual, com caules solteiros, erecto e normalmente de 1 a $3 \mathrm{~m}$, e ocasionalmente com $4 \mathrm{~m}$ de altura. Caules maciços, glabros, exceto acima dos cachos e dos nós, que são pilosos. Folhas com 20 a $100 \mathrm{~cm}$ de comprimento por 5 a $50 \mathrm{~mm}$ de largura. Inflorescência em panículas contraídas com 10 a $50 \mathrm{~cm}$ de comprimento e de 0,5 a $4 \mathrm{~cm}$ de diâmetro. O eixo piloso da panicula é cercado por numerosos pedicelos com 2 a $25 \mathrm{~mm}$ de comprimento cada um, suportando de 25 a 90 cerdas, alguns deles plumosos e solitários ou agrupados em duas a cinco espiguetas. As espiguetas, de $4 \mathrm{~cm}$ de comprimento e, as flores inferiores, estaminadas. Nos cultivares graníferos, as cariōpses são largas, com $4 \mathrm{~mm}$ de comprimento, aproximadamente, de coloração cinza, amarelo-palha, branca ou levamente azulada, porém, nos tipos selvagens ou naturalizados, podem ser muito menores (BOGDAN, 1976).

Sob condições controladas sementes de milheto forrageiro Pennisetum americanum cultivar "Bulk l", foram colocadas para germinar em vasos plásticos com capacidade para $5 \mathrm{~kg}$, de silica finamente moída como substrato. A ger- 
minação teve início dois dias após, quando as plântulas passạ ram a receber solução completa modificados por SARRUGE (1975), diluída 1:5, durante dezoito dias, quando procedeu-se o desbaste, de $\underline{1}$ xando apenas três plantas por vaso. Nos quatro dias que ante cederam o início da fase experimental, percolou-se água desmi neralizada nos vasos, no mínimo três vezes ao dia, visando a eliminação de possíveis resíduos da solução completa diluída. Foram aplicados sete níveis de cálcio:0-50 ppm, 100 ppm, $150 \mathrm{ppm}, 200 \mathrm{ppm}, 250 \mathrm{ppm} \mathrm{e} 300 \mathrm{ppm}$, de acordo com a seguinte formulação das soluções nutritivas, em ml por litro de solução, conforme assinalam os dados abaixo.

\begin{tabular}{|c|c|c|c|c|c|c|c|c|}
\hline $\begin{array}{l}\text { Solução } \\
\text { estoque }\end{array}$ & $\frac{\mathrm{pm}}{\mathrm{al}} \mathrm{l}$ cio & 0 & 50 & 0 & 150 & 200 & 250 & 300 \\
\hline $\mathrm{KH}_{2} \mathrm{PO}$ & $1 \mathrm{M} *$ & 1 & 1 & 1 & 1 & 1 & 1 & 1 \\
\hline $\mathrm{KCl}$ & $1 \mathrm{M}$ & 5 & 5 & 5 & 5 & 5 & 5 & 5 \\
\hline $\mathrm{CaCl}_{2}$ & $1 \mathrm{M}$ & - & 1,25 & 2,5 & 2,5 & 2,5 & 2,5 & 2,5 \\
\hline $\mathrm{NH}_{4} \mathrm{Cl}$ & $1 M$ & 5 & 2,5 & - & - & - & - & - \\
\hline $\mathrm{NH}_{4} \mathrm{NO}_{3}$ & $1 \mathrm{M}$ & 5 & 8,25 & 7,5 & 6,25 & 5 & 3,75 & 2,5 \\
\hline $\mathrm{MgSO}_{4}$ & $1 \mathrm{M}$ & 2 & 2 & 2 & 2 & 2 & 2 & 2 \\
\hline $\mathrm{Ca}\left(\mathrm{NO}_{3}\right)_{2}$ & $1 \mathrm{M}$ & - & - & - & 1,25 & 2,5 & 3,75 & 5 \\
\hline Micro-Fe & & 1 & 1 & 1 & 1 & 1 & 1 & 1 \\
\hline Fe EDTA & & 1 & 1 & 1 & 1 & 1 & 1 & 1 \\
\hline
\end{tabular}

* M = solução molar

As soluções foram percoladas no mínimo três vezes ao dia, sendo o seu volume completado para um litro com 
água desmineralizada, diariamente, enquanto que a renovação das soluções era processada a cada cinco dias.

$$
\text { Decorridos trinta e oito dias, procedeu-se o }
$$

corte das plantas, sendo o material separado em folhas adjacentes (as duas mais próximas da espiga), folhas não adjacentes, espigas e colmos. O material foi lavado em água destila da, sendo em seguida colocado para secar em estufa a $75^{\circ} \mathrm{C}$. Após a secagem, determinou-se o peso da matéria seca, procedendo-se a moagem do material. As amostras foram analisadas para N, P, K, Ca, Mg, B, Cu, Fe, Mn e $\mathrm{Zn}$, de acordo com os mé todos descritos por SARRUGE \& HAAG (1974). Foi feita uma aná lise de regressão e determinou-se também as interações entre os diferentes tratamentos aplicados ao milheto forrageiro.

Utilizou-se o delineamento inteiramente casua lizado, com sete tratamentos e quatro repetições. As médias foram comparadas através do teste de Tukey. 


\section{RESULTADOS E DISCUSSÃO}

\subsection{Producão de matéria seca}

A Tabela 1, apresenta a produção total de maté ria seca do milheto forrageiro, obtida em função da aplicação dos diferentes níveis de cálcio, cujo corte foi efetuado aos trinta e oito dias, quando as plantas haviam completado seu ciclo vegetativo.

TABELA 1. Produção total de matéria seca do milheto forrageiro, obtida em função dos tratamentos aplicados. Média de quatro repetições, com três plantas/vaso.

\begin{tabular}{cc}
\hline $\begin{array}{c}\text { Nível Ca } \\
(\mathrm{ppm})\end{array}$ & $\begin{array}{c}\text { Médias * } \\
(\mathrm{g})\end{array}$ \\
\hline 0 & $35,5 \mathrm{C}$ \\
50 & $54,6 \mathrm{AB}$ \\
100 & $63,0 \mathrm{AB}$ \\
150 & $65,2 \mathrm{AB}$ \\
200 & $69,5 \mathrm{~A}$ \\
250 & $49,1 \mathrm{BC}$ \\
300 & $55,9 \mathrm{AB}$ \\
\hline Médias acompanhadas de letras diferentes diferem ao nível \\
de l\% de probabilidade.
\end{tabular}


Verifica-se que a produção obtida no nível de 200 ppm, diferiu da obtida no nível de 0 ppm, não havendo diferença entre os demais niveis.

Tal fato reforça a importância que o cálcio exerce na produção de matéria seca das culturas, sendo concordante com o trabalho de LOPES (1983) que determinou o teor de cálcio trocável em diversas amostras de solo sob vegetação de cerrado, cujo teor variou de 0,04 a $6,81 \mathrm{meq} / \mathrm{l} 00 \mathrm{~g}$, com média de 0,25 meq/l00g. Segundo o autor, das amostras analisadas, uma alta porcentagem apresentava uma considerável deficiência de cálcio para a maioria das culturas. Segundo deter minação de GONZALES-ERICO (1976), a concentração média de cál cio solúvel para Latossolo Vermelho da região do Brasil Central é de 1,2 mg/1, enquanto PAVAN (1983), no Paraná encontrọ concentrações de cálcio inferiores a $5 \mathrm{mg} / \mathrm{l}$, para os solos ácidos.

A Figura 1, apresenta a interação exercida pelos diferentes níveis de cálcio, sobre a produção de matéria seca do milheto forrageiro, 
10 .

gMS/Naso

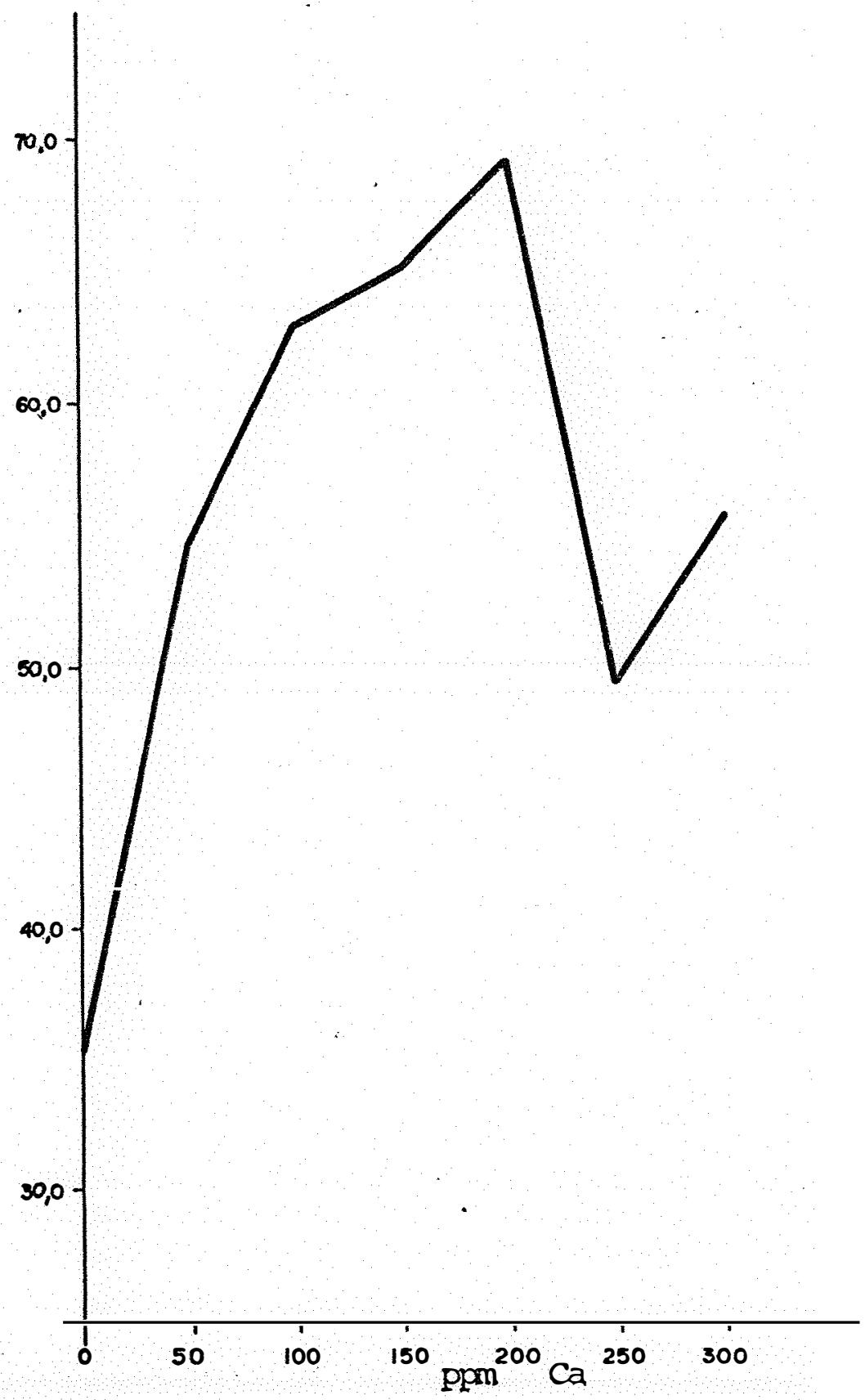

FIGURA 1. Produção (Y) de matêria seca total (g), obtida em função dos diferentes níveis de cálcio (X) aplicados ao milheto forrageiro. 


\subsection{Concentragẽo dos nUtrientes}

\subsubsection{NITROGENIO}

A concentração de nitrogênio nas diferentes partes do milheto forrageiro, diferiu em função dos diversos níveis de cálcio aplicados, exceto para as folhas não adjacên tes, como se observa na Tabela 2

Verifica-se nas folhas adjacentes, uma variação de 2,16\%, determinada no tratamento em que foi aplicado 50 ppm de cálcio, correspondendo a 13,4\% de proteína bruta, até $1,52 \%$ de $N$, para $\circ$ nível de 200 ppm, equivalente a 9,5\% de $\mathrm{PB}^{*}$.

Nas folhas "não adjacentes", a concentração de nitrogênio não foi influenciada pelos níveis de Ca, cuja variação foi de 1,05\%, determinado com o nível 200 ppm de cálcio, até $1,48 \%$ de $\mathrm{N}$, no tratamento testemunha, correspondendo a 6,6 e $9,3 \%$ de proteína bruta.

Nas espigas, o teor de nitrogênio foi influenciado pela aplicação dos tratamentos. Observou-se uma variação de 1,46\%, determinada no nível de 100 ppm de cálcio, até $2,28 \%$ de $\mathrm{N}, \circ$ que se equivale a 9,1 e $14,2 \%$ de proteína bruta, respectivamente.

Nos colmos, a concentração apresentou uma variação de 0,57\%, com a aplicação de 200 ppm de cálcio, sendo 
aproximádamente $3,6 \%$ de proteína bruta, até $1,1 \%$ de $N$, determinado no nível de 250 ppm de cálcio correspondendo a 6,8\% de $\mathrm{PB}$.

HESTER \& SHELDON (1936) verificaram que solos com alta saturação de cálcio, deprimiu a absorção de nitrogênio, quando trabalharam com Phaseolus vulgaris CARVALHO et alii (1980) estudaram a performance de três espécies de stílosantes em três tipos de solos ácidos. Segundo os autores, a calagem promoveu as mais diferentes influências sobre a absorção de nitrogênio pelas plantas. Entretanto, eles afirmam que as mais altas doses de calagem aplicaḍas reduziram a absorção de nitrogênio na parte aérea das plantas.

TABELA 2. Valores de $\mathrm{N}(\%)$, determinados nas folhas adjacentes, folhas não adjacentes, espigas e colmos do milheto forrageiro, em função dos diferentes niveis de cálcio aplicados. Média de quatro repetições com três plantas/vaso.

\begin{tabular}{ccccc}
\hline $\begin{array}{c}\text { Nivel Ca } \\
(\mathrm{ppm})\end{array}$ & $\begin{array}{c}\text { Folhas } \\
\text { adjacentes }\end{array}$ & $\begin{array}{c}\text { F não } \\
\text { adjacentes }\end{array}$ & Espiga & Colmo \\
\hline 0 & $1,95 \mathrm{ab}$ & $1,48 \mathrm{~A}$ & $2,28 \mathrm{~A}$ & $1,09 \mathrm{ab}$ \\
50 & $2,16 \mathrm{a}$ & $1,27 \mathrm{~A}$ & $1,84 \mathrm{AB}$ & $0,81 \mathrm{ab}$ \\
100 & $1,53 \mathrm{~b}$ & $1,33 \mathrm{~A}$ & $1,46 \mathrm{~B}$ & $0,65 \mathrm{ab}$ \\
150 & $1,56 \mathrm{~b}$ & $1,12 \mathrm{~A}$ & $1,89 \mathrm{AB}$ & $0,61 \mathrm{ab}$ \\
200 & $1,52 \mathrm{~b}$ & $1,05 \mathrm{~A}$ & $1,51 \mathrm{~B}$ & $0,57 \mathrm{~b}$ \\
250 & $1,56 \mathrm{~b}$ & $1,32 \mathrm{~A}$ & $1,49 \mathrm{~B}$ & $1,10 \mathrm{a}$ \\
300 & $1,84 \mathrm{ab}$ & $1,36 \mathrm{~A}$ & $1,63 \mathrm{AB}$ & $0,64 \mathrm{ab}$ \\
\hline C.V. & $14,4 \%$ & $19,3 \%$ & $15,4 \%$ & $28,7 \%$ \\
\hline
\end{tabular}

* Médias acompanhadas de letras maiúsculas diferem ao nível de $1 \%$ e de minúscula ao nível de $5 \%$ de probabilidade. 
Os valores de nitrogênio determinados por FRAN ÇA et alii. (1987), cujas concentrações estavam assim distribuidas: a) folhas adjacentes - 3,21\% de $\mathrm{N}$ e $20,1 \% \mathrm{~PB} ; \mathrm{b})$ folhas não adjacentes - 2,66\% - 16,6\% PB; c) espigas - 2,51\% de $\mathrm{N}$ e $15,7 \%$ e d) colmos - 1,87\% de $\mathrm{N}$ e $11,7 \%$ de proteína bruta, são bastante superiores aos valores determinados em função dos diferentes níveis de cálcio aplicados, conforme se observa na Tabela 2 , uma vez que, os teores médios calculados para as diversas partes da forrageira foram da seguinte odem: folhas adjacentes - 1,72\% - 10,7\% PB; b) folhas não -adjacentes - 1,27\% - 7,9\% $\mathrm{PB}$; c) espigas - 1,73\% - 10,8\% $\mathrm{PB}$ e d) $\mathrm{co} \underline{1}$ mos - 0,78\% de $\mathrm{N}-4,8 \%$ de proteína bruta. Tais valores comprovam que os diferentes tratamentos aplicados ao milheto for rageiro, deprimiram a absorção de nitrogênio na parte aérea das plantas, sendo portanto, concordantes com HESTER \& SHELTON (1936).

A análise da regressão revelou significância, apenas para a interação do cálcio e a concentração de nitrogênio nas folhas não adjacentes, conforme se observa na Figura 2 .

Com relação à nutrição animal, os teores de proteína bruta (PB) determinados nas diferentes partes da planta, atendem às exigências nutricionais dos bovinos, tendo em vista, que os menores valores foram concentrados nos colmos, com um teor médio de 4,8\%. Segundo MILFORD \& MINSON (1965) a ingestão de forragem torna-se restrita, a partir do momento, em que o teor de proteína da dieta torna-se inferior 
14 .

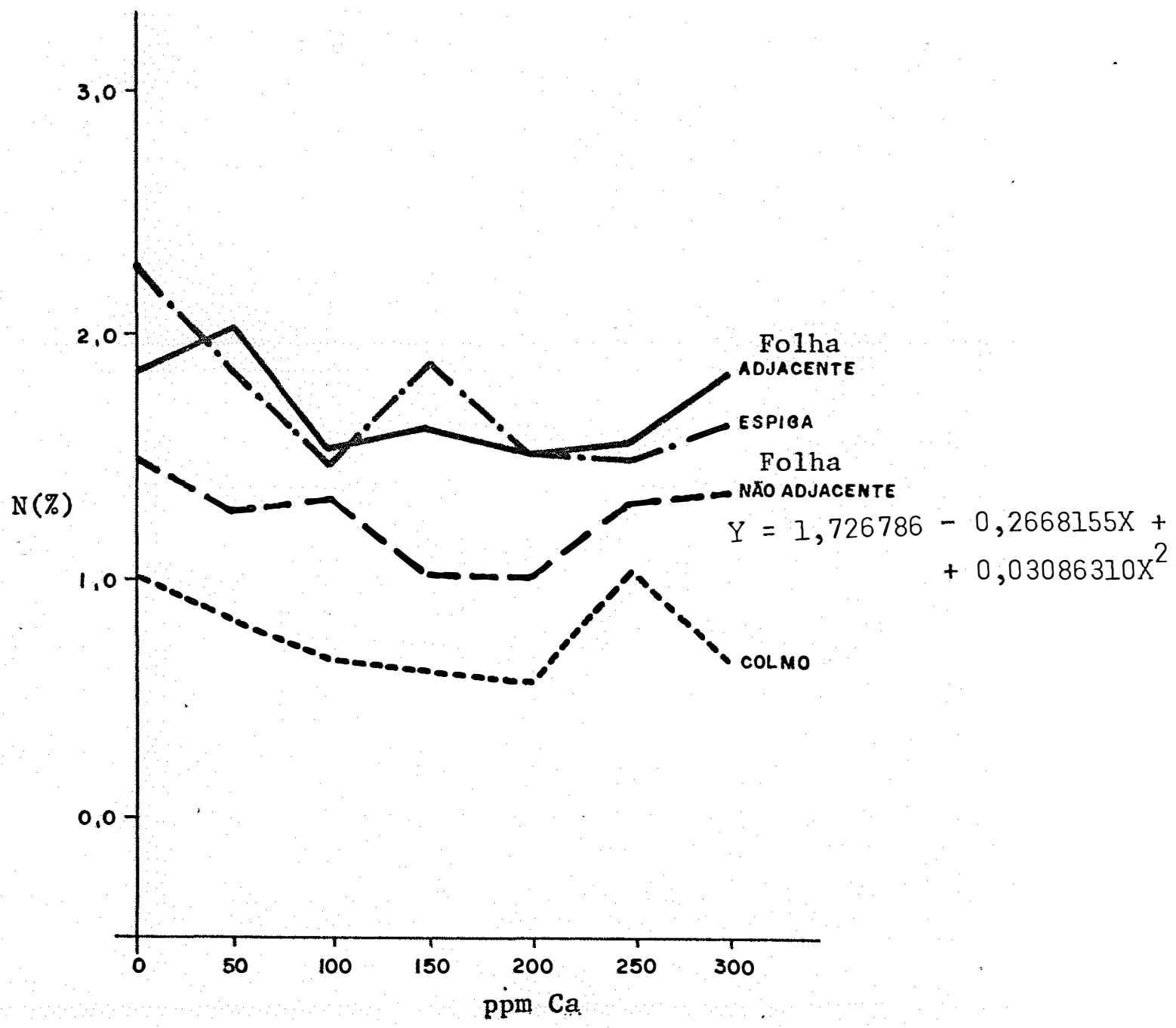

FIGURA 2. Teores de nitrogênio ( $\%$ ), determinados nas diferentes partes do milheto forrageiro, em função dos niveis de cálcio aplicados. 
a 7\% e que esta limitação ocorre mais frequentemente com gramineas tropicais. Entretanto, CAIELLI et alii (1974), relatam que um teor de proteína bruta igual a 4,8\% na matéria seca da dieta é suficiente para evitar a perda de peso dos bovi nos no Estado de São Paulo.

\subsubsection{FÓSFORO}

A aplicação dos diferentes níveis de cálcio, exerceu influência sobre a concentração de fósforo nas diversas partes do milheto forrageiro, com exceção das espigas.

Observa-se na Tabela 3 , uma variação de $0,14 \%$ de $\mathrm{P}$ determinado com aplicação de 150 ppm de cálcio, até $0,31 \%$ de $\mathrm{P}$, encontrado nas folhas adjacentes, no tratamento testemunho.

Para as folhas não adjacentes, a exemplo do que ocorreu anteriormente, observou-se uma variação de 0,07\%, em função da aplicação de $150 \mathrm{ppm}$ de cálcio, até 0,28\% de P, determinado no tratamento tescemunho.

Nas espigas, a concentração de fósforo não diferiu em função dos tratamentos aplicados, embora tenha apresentado uma variação de 0,19 a $0,29 \%$ de $P$.

Nos colmos, a concentração de fósforo diferiu em função dos tratamentos aplicados, apresentando uma variação de 0,05\%, com o nível de 150 ppm de cálcio, até 0,20\% de P, no tratamento testemunho. 
TABELA 3. Valores de $P(\%)$, determinados nas folhas adjacentes, folhas não adjacentes, espigas e colmos do milheto forrageiro, em função dos diferentes níveis de cálcio aplicados. Média de quatro repetições com três plantas/vaso.

\begin{tabular}{ccccc}
\hline $\begin{array}{c}\text { Nivel Ca } \\
\text { (ppm) }\end{array}$ & $\begin{array}{c}\text { Folhas } \\
\text { adjacente }\end{array}$ & $\begin{array}{c}\text { F não } \\
\text { adjacente }\end{array}$ & Espiga & Colmo \\
\hline 0 & $0,31 \mathrm{~A}$ & $0,28 \mathrm{~A}$ & $0,29 \mathrm{~A}$ & $0,20 \mathrm{~A}$ \\
50 & $0,25 \mathrm{AB}$ & $0,19 \mathrm{~B}$ & $0,24 \mathrm{~A}$ & $0,09 \mathrm{CD}$ \\
100 & $0,28 \mathrm{AB}$ & $0,17 \mathrm{~B}$ & $0,20 \mathrm{~A}$ & $0,13 \mathrm{BC}$ \\
150 & $0,14 \mathrm{~B}$ & $0,07 \mathrm{C}$ & $0,19 \mathrm{~A}$ & $0,05 \mathrm{D}$ \\
200 & $0,20 \mathrm{AB}$ & $0,07 \mathrm{C}$ & $0,23 \mathrm{~A}$ & $0,08 \mathrm{CD}$ \\
250 & $0,31 \mathrm{~A}$ & $0,20 \mathrm{~B}$ & $0,29 \mathrm{~A}$ & $0,17 \mathrm{AB}$ \\
300 & $0,24 \mathrm{AB}$ & $0,10 \mathrm{C}$ & $0,27 \mathrm{~A}$ & $0,07 \mathrm{CD}$ \\
\hline $\mathrm{C} . \mathrm{V}$. & $22,4 \%$ & $14,8 \%$ & $18,8 \%$ & $23,2 \%$ \\
\hline
\end{tabular}

* Médias acompanhadas de letras maiúsculas diferem ao nível de $1 \%$ de probabilidade.

O baixo Indice de $\mathrm{pH}$ do solo, concentrações tó xicas de alumínio livre e manganês e deficiência de cálcio e magnésio, são alguns dos fatores limitantes do desenvolvimen to das pastagens nas regiões tropicais (SCHMEHL et alii, 1950 e HEWITT, 1952). Segundo WHITE \& TAYLOR (1977) a calagem promove uma diminuição da concentração de fosfatos na solução, através da redução da quantidade de fosfatos trocável ou pelo aumento da absortividade do fosfato. Segundo AMARASIRI 
\& OLSEN (1973) a adição de fosfatos promove a formação de precipitados de baixa solubilidade (Ca - Fe e fosfatos de Al), que reduzem a disponibilidade de fosfatos. A precipitação de fosfatos de cálcio é promovida por altas concentrações de cálcio na solução do solo segundo MENGEL \& KIRKBY (1982).

Existem relatos conflitantes com relação aos efeitos da calagem sobre o fosfato trocável. Se a calagem au menta o fosfato trocável, deveria também aumentar o fosfato solúvel e vice-versa. O cálcio estimula a absorção de fosfatos pelas raízes das plantas (TANADA, 1955; LEGGETT et alii, 1965 e FRANKLIN, 1969). ROBSON et alii. (1970) observaram que a proporção que se aumenta a concentração de cálcio na solução, aumentava significativamente a absorção de fósforo pela cevada. CARVALHO et alii. (1980), observaram que o efeito da calagem sobre a concentração de fósforo, em diferentes tipos de solos e diversas espécies de stylosanthes, foi muito variável, mas que de um modo geral, houve uma tendência de dimí nuição da concentração de fósforo nas plantas, à medida que se aumentavam as doses de calcário. Trabalho conduzido por FRANÇA et alii (1987) com solução nutritiva completa e com omissão de macronutrientes, os valores de fósforo concentrados nas diferentes partes do milheto forrageiro, são bastante superiores àqueles determinados na mesma espécie forrageira, quando submetida aos diferentes níveis de cálcio. Para as plantas submetidas à solução nutritiva completa, os autores determinaram teores de $0,38 \%, 0,15 \%, 0,58 \%$ e $0,14 \%$ de P, con- 
centrados nas folhas adjacentes, não adjacentes, espigas e nos colmos, respectivamente. Para as plantas submetidas aos diferentes níveis de cálcio, para as mesmas partes da forrageira, determinou-se um teor médio, que foi de $0,24 \%, 0,15 \%$, $0,24 \%$ e $0,11 \%$ de $P$, respectivamente. Portanto, estes resultados demonstraram claramente que os diferentes niveis de cálcio aplicados ao milheto, deprimiram a absorção de fósforo pela forrageira.

A análise da regressão revelou significância, apenas para a interação dos tratamentos aplicados e a concentração de fósforo das espigas do milheto forrageiro, conforme se observa na Figura 3.

Do ponto de vista da nutrição animal, o NRC* (1978) recomenda $0,34 \%$ de fósforo na matéria seca da dieta, em se tratando de uma vaca com $400 \mathrm{~kg}$, com uma produção entre 8 e $13 \mathrm{~kg}$ de leite/dia.

Com relação a gado de corte, o NRC (1975)， recomenda para animais em crescimento $0,26 \%$ e animais adultos $0,18 \%$ de fósforo. Para vacas com $500 \mathrm{~kg}$ de peso vivo e com uma produção inferior a $11 \mathrm{~kg}$ de leite por dia, a exigência é de $0,31 \%$ na matéria seca da dieta NRC (1978).

* NRC - National Research Council. 


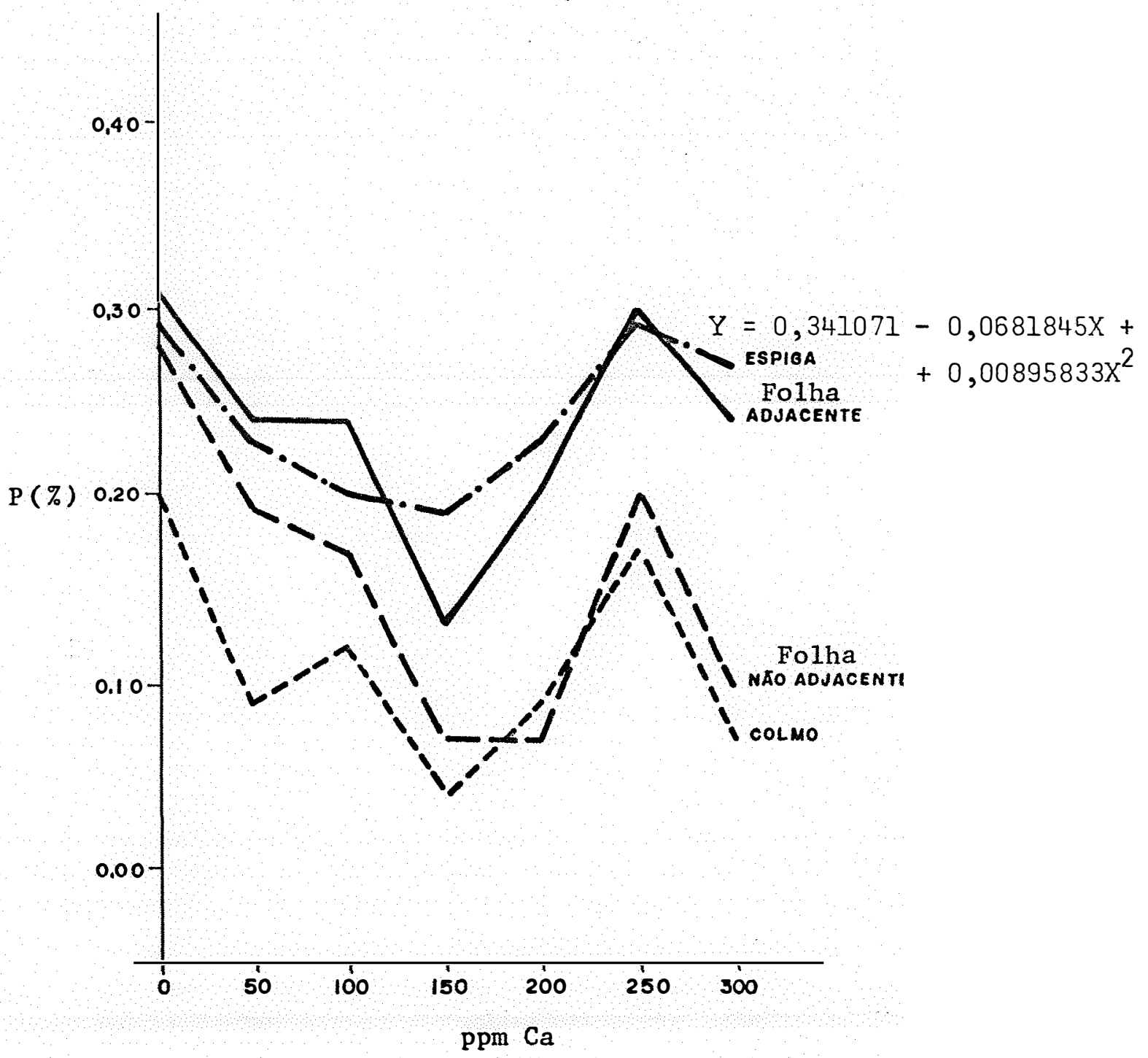

FIGURA 3. Teores de fósforo $(\%)$, determinados nas diferentes partes do milheto forrageiro, em função dos níveis de cálcio aplicados. 
De acordo com a Tabela 4, a aplicação dos dife rentes niveis de cálcio no milheto forrageiro, exerceu influência na concentração do potássio nas folhas "não adjacentes", espiga e nos colmos.

TABELA 4. Valores de $\mathrm{K}(\%)$, determinados nas folhas adjacen tes, folhas não adjacentes, espigas e colmos do milheto forrageiro, em função dos diferentes niveis de cálcio aplicados. Média de quatro repetições com três plantas/vaso.

\begin{tabular}{rccll}
\hline $\begin{array}{c}\text { Nivel Ca } \\
(\mathrm{ppm})\end{array}$ & $\begin{array}{c}\text { Folhas } \\
\text { adjacentes }\end{array}$ & $\begin{array}{c}\text { F não } \\
\text { adjacentes }\end{array}$ & Espiga & Colmo \\
\hline 0 & $3,02 \mathrm{~A}$ & $2,75 \mathrm{~A}$ & $1,53 \mathrm{~A}$ & $1,97 \mathrm{AB}$ \\
50 & $2,22 \mathrm{~A}$ & $2,29 \mathrm{AB}$ & $1,17 \mathrm{ABC}$ & $1,29 \mathrm{~B}$ \\
100 & $2,24 \mathrm{~A}$ & $1,95 \mathrm{~B}$ & $0,83 \mathrm{C}$ & $1,97 \mathrm{AB}$ \\
150 & $2,25 \mathrm{~A}$ & $1,75 \mathrm{~B}$ & $1,05 \mathrm{BC}$ & $1,67 \mathrm{~B}$ \\
200 & $3,23 \mathrm{~A}$ & $1,77 \mathrm{~B}$ & $1,37 \mathrm{AB}$ & $2,77 \mathrm{~A}$ \\
250 & $2,26 \mathrm{~A}$ & $2,27 \mathrm{AB}$ & $1,36 \mathrm{AB}$ & $1,70 \mathrm{~B}$ \\
300 & $2,24 \mathrm{~A}$ & $2,07 \mathrm{AB}$ & $1,26 \mathrm{ABC}$ & $1,34 \mathrm{~B}$ \\
\hline C.V. & $20,0 \%$ & $12,7 \%$ & $13,2 \%$ & $20,0 \%$ \\
\hline
\end{tabular}

* Médias acompanhadas de letras maiúsculas diferem ao nível de $1 \%$ de probabtlidade.

Nas folhas não adjacentes, observa-se uma variação de $2,75 \%$, encontrado no tratamento testemunho, até 
1,75\%, determinado para o nível de 150 ppm de aplicação de cálcio.

Nas espigas, a aplicação dos diferentes tratamentos também influenciou a concentração do potássio. Observa-se que os teores variaram de $1,53 \%$ no tratamento testemunho, até $0,83 \%$ de potássio, com a aplicação de 100 ppm de cál cio.

Nos colmos, a exemplo das espigas, a aplicação dos diferentes tratamentos, revelou significância em rela ção à concentração do potássio. Observou-se uma variação de 2,77\%, para o tratamento testemunho, até 1,29\% de potássio, determinado com a aplicação de 50 ppm de cálcio.

De um modo geral, observa-se que as menores concentrações de potássio, ocorreram nos tratamentos em que foram aplicadas as menores doses de cálcio. Segundo ELZAM \& HODGES (1967) e NWACHUKI (1968) a absorção de potássio pode ser estimulada ou inibida pelo cálcio, dependendo da espécie de planta e da concentração dos cátions envolvidos.

De acordo com a tendência que foi observada, pa ra as maiores concentrações de potássio nas diferentes partes do milheto forrageiro, sempre nos tratamentos em que foram feitas as menores aplicações de cálcio, os resultados aqui obtidos, são concordantes com KAN \& HANSON (1967), EPSTEIN (1961), JACOBSON et alii (1961), WAISEL (1962) e RANS et alii (1964), que afirmam que normalmente o cálcio diminui a absorção de ions menos hidratados como o potássio. Verifica-se que em alguns casos o cálcio proporcionou um aumento da absorção 
22 .

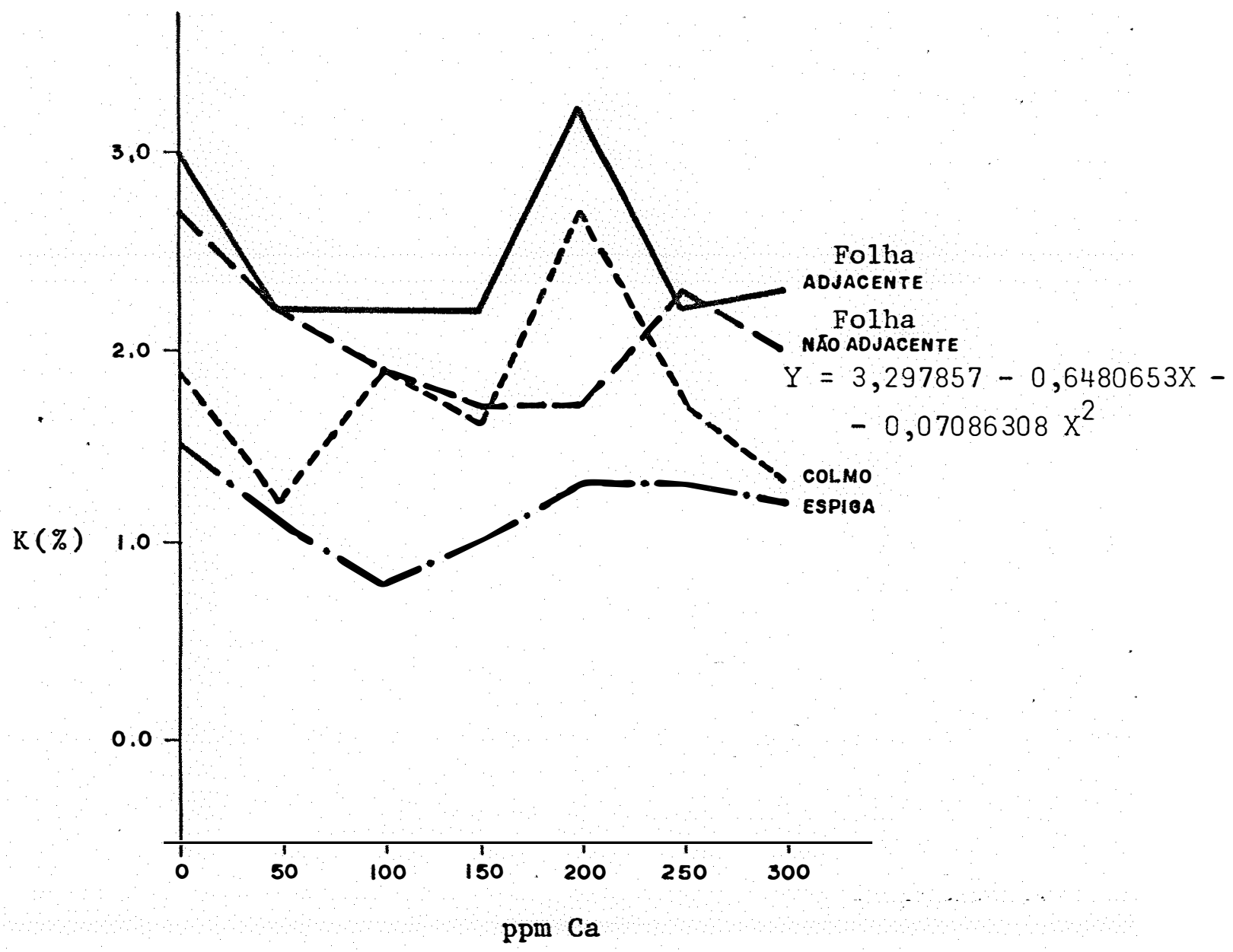

FIGURA 4. Teores de potássio ( $\%$ ), determinados nas diferentes partes do milheto forrageiro, em função dos níveis de cálcio aplicados. 
de potássio, enquanto em outros houve inibição. Tais alternâncias, indicam que o cálcio pode estimular, inibir ou até mesmo não ter efeito, dependendo das concentrações do potássio e de cálcio segundo hOOYMANS (1964) e HAITT (1970). Os au tores, enquanto ilustram que o cálcio pode não consistentemen te, inibir ou estimular a absorção de cátions monovalentes, eles não demonstram de uma forma clara, o mecanismo pelo qual o cálcio exerce esse efeito.

A anālise de regressão não revelou significância entre os níveis de cálcio aplicados no milheto forrageiro e a concentração de potássio nas diferentes partes da planta.

Com relação à nutrição animal, o NRC (1978) re comenda $0,80 \%$ de potássio na dieta, para uma vaca com uma pro dução de 8 a $18 \mathrm{~kg}$ de leite/dia. Para o gado de corte, o NRC (1976) sugere 0,65\%, enquanto $0 A R C^{*}(1980)$ recomenda $0,5 \%$ para vadas em gestação.

\subsubsection{CÁLCIO}

Observa-se na Tabela 5 , que a concentração de cálcio nas diferentes partes do milheto forrageiro, foi influenciada de forma significativa, em função dos tratamentos aplicados.

Para as folhas adjacentes, foi observada uma variação de $0,80 \%$, no tratamento em que foi aplicado 300 ppm

* ARC - Agricultural Research Council. 
de cálcio, até a faixa de $0,17 \%$ de $\mathrm{Ca}$, determinado no tratamento testemunho.

TABELA 5. Valores de Ca $(\%)$, determinados nas folhas adjacen tes, folhas não adjacentes, espigas e colmos do milheto forrageiro, em função dos diferentes níveis de cálcio aplicados. Média de quatro repetições com três plantas/vaso.

\begin{tabular}{ccccc}
\hline $\begin{array}{c}\text { Nivel Ca } \\
\text { (ppm) }\end{array}$ & $\begin{array}{c}\text { Folhas } \\
\text { adjacentes }\end{array}$ & $\begin{array}{c}\text { F não } \\
\text { adjacentes }\end{array}$ & Espiga & Colmo \\
\hline 0 & $0,17 \mathrm{C}$ & $0,24 \mathrm{C}$ & $0,05 \mathrm{D}$ & $0,05 \mathrm{~B}^{*}$ \\
50 & $0,37 \mathrm{BC}$ & $0,47 \mathrm{BC}$ & $0,07 \mathrm{CD}$ & $0,09 \mathrm{~B}$ \\
100 & $0,59 \mathrm{AB}$ & $0,74 \mathrm{AB}$ & $0,07 \mathrm{CD}$ & $0,23 \mathrm{~A}$ \\
150 & $0,68 \mathrm{AB}$ & $0,93 \mathrm{AB}$ & $0,15 \mathrm{ABC}$ & $0,23 \mathrm{~A}$ \\
200 & $0,62 \mathrm{AB}$ & $0,97 \mathrm{~A}$ & $0,11 \mathrm{BCD}$ & $0,26 \mathrm{~A}$ \\
250 & $0,79 \mathrm{~A}$ & $1,08 \mathrm{~A}$ & $0,16 \mathrm{AB}$ & $0,22 \mathrm{~A}$ \\
300 & $0,80 \mathrm{~A}$ & $1,06 \mathrm{~A}$ & $0,21 \mathrm{~A}$ & $0,23 \mathrm{~A}$ \\
\hline $\mathrm{C}$ & $20,7 \%$ & $20,6 \%$ & $25,7 \%$ & \\
\hline
\end{tabular}

Médias acompanhadas de letras maiúsculas diferem ao nível de $1 \%$ de probabilidade.

Nas folhas não adjacentes, foi determinada uma concentração de 1,08\%, no tratamento com aplicação de 250 ppm de cálcio, até $0,23 \%$ de cálcio para o tratamento testemunho. Nas espigas, a concentração máxima, foi determinada no tratamento com a dose mais elevada de aplicação, a 
cançando $0,20 \%$, enquanto o tratamento testemunho

concentrou apenas $0,05 \%$ de cálcio.

Finalmente, para os colmos, a exemplo do ocorrido nas demais partes da forrageira, as maiores concentrações foram observadas sempre em função dos maiores nívels de cálcio aplicado. Verifica-se que a maior concentração, $0,27 \%$ foi determinada para o nível de 200 ppm de cálcio, enquanto a menor concentração também foi observada no tratamento testemunho.

A concentração de cálcio na parte aérea do milheto forrageiro, de um modo geral, apresentou um crescimento linear em função dos tratamentos aplicados. HOLFORD (1985), verificou que a nível de solo, a calagem promoveu aumentos significativos da concentração de cálcio, quando trabalhou com trevo branco. FRANÇA et alii (1987), em trabalho conduzido em casa de vegetação, com solução nutritiva completa, determinaram teores de cálcio correspondentes a $0,52 \%, 0,92 \%, 0,27 \%$ e 0,53\%, para as folhas adjacentes, folhas não adjacentes, es pigas e colmos do milheto forrageiro. Os teores médios de cálcio, determinados para as mesmas partes da forrageira, quando submetida aos diferentes níveis de cálcio são inferiores aos teores concentrados na presença de solução completa, com exceção apenas para as folhas adjacentes. Desta forma, è pos sível evidenciar o efeito depressivo de altas concentrações do cálcio na absorção do elemento.

A anālise da regressão revelou-se linearmente para a concentração do cálcio nas partes aérea do milheto for 


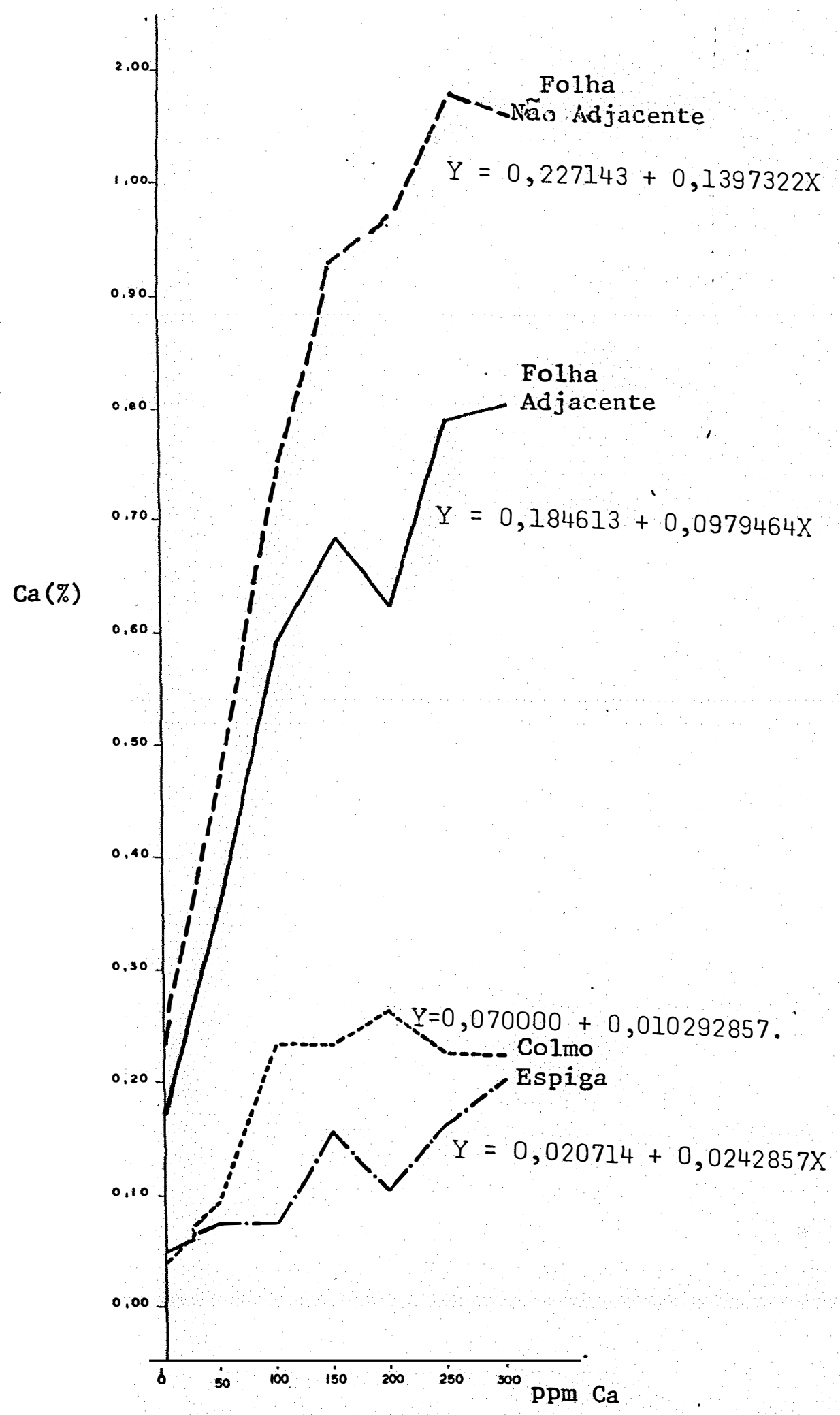

FIGURA 5. Teores de cálcio $(\%)$, determinados nas diferentes partes do milheto forrageiro, em função dos níveis de cálcio aplicados. 
rageiro; em função dos tratamentos aplicados, conforme se observa na Figura 5 .

Com relação à nutrição animal, a recomendação do NRC (1976) para novilhos de corte em crescimento é de $0,18 \%$ a $1,04 \%$ de cálcio. Para vacas com $500 \mathrm{~kg}$ e capacidade de produção inferior a $11 \mathrm{~kg} / \mathrm{dia}$, a recomendação do NRC (1978) é de $0,43 \%$, em relação à matéria seca da dieta. Verifica-se, portanto, que embora os tratamentos tenham deprimido a absorção do nutriente, os valores determinados para as folhas adją centes e não adjacentes atendem perfeitamente as recomenda ções citadas. Entretanto, os teores encontrados nas espigas se situam abaixo das exigências, enquanto os determinados nos colmos se encontram no limite mínimo.

\subsubsection{MAGNESIO}

A aplicação dos diferentes tratamentos no milheto forrageiro, exerceu influência apenas na concentração de magnésio nas espigas e nos colmos.

Nas folhas adjacentes, a concentração de magnésio não diferiu dentre os diversos níveis de cálcio aplica do, sendo a variação de $0,53 \%$, no tratamento em que foi aplicado $200 \mathrm{ppm}$ de cálcio, atè 0,28\%, para o tratamento testemunho.

Para as folhas nao adjacentes, a exemplo do ocorrido anteriormente, as concentrações variaram de 0,59\%, com a aplicação de $150 \mathrm{ppm}$ de cálcio, até $0,42 \%$, para o nível de 50 ppm de cálcio. 
TABELA 6. Valores de Mg (\%), determinados nas folhas adjacen tes, folhas não adjacentes, espigas e colmos do miTheto forrageiro, em função dos diferentes níveis de cálcio aplićados. Média de quatro repetições om três plantas/vaso.

\begin{tabular}{|c|c|c|c|c|}
\hline $\begin{array}{l}\text { NÍ vel Ca } \\
\quad(\mathrm{ppm})\end{array}$ & $\begin{array}{l}\text { Folhas } \\
\text { adjacentes }\end{array}$ & $\begin{array}{l}\text { F. não } \\
\text { adjacentes }\end{array}$ & Espiga & Colmo \\
\hline 0 & $0,28 \mathrm{~A}$ & $0,45 \mathrm{~A}$ & $0,22 \mathrm{AB}$ & $0,25 \mathrm{~A}^{*}$ \\
\hline 50 & $0,36 \mathrm{~A}$ & $0,42 \mathrm{~A}$ & $0,17 \mathrm{~B}$ & $0,19 \mathrm{~A}$ \\
\hline 100 & $0,37 \mathrm{~A}$ & $0,47 \mathrm{~A}$ & $0,16 \mathrm{~B}$ & $0,22 \mathrm{~A}$ \\
\hline 150 & $0.51 \mathrm{~A}$ & $0,59 \mathrm{~A}$ & $0,25 \mathrm{AB}$ & $0,30 \mathrm{~A}$ \\
\hline 200 & $0,53 \mathrm{~A}$ & $0,49 \mathrm{~A}$ & $0,33 \mathrm{~A}$ & $0,38 \mathrm{~A}$ \\
\hline 250 & $0,43 \mathrm{~A}$ & $0,51 \mathrm{~A}$ & $0,23 \mathrm{AB}$ & $0,28 \mathrm{~A}$ \\
\hline 300 & $0,48 \mathrm{~A}$ & 0.59 A & $0,24 \mathrm{AB}$ & $0,30 \mathrm{~A}$ \\
\hline C. V. & $30,8 \%$ & $19,8 \%$ & $20,9 \%$ & $28,7 \%$ \\
\hline
\end{tabular}

* Médias acompanhadas de letras maiúsculas diferem ao nível de $1 \%$ de probabilidade.

Nas espigas, observou-se uma variação de $0,33 \%$, com a aplicação de 200 ppm de cálcio, até 0,16\%, no nível de $100 \mathrm{ppm}$ de cálcio, enquanto para os colmos, a variação foi de $0,38 \%$, determinada no tratamento com 200 ppm, até 0,19\%, para o nível de 60 ppm de cálcio aplicado.

o cálcio pode efetivamente afetar a absorção de magnésio. o cálcio inibiu a absorção de magnésio de raízes cortadas e intactas de cevada segundo MAAS \& OGATA (1971) 
29 .

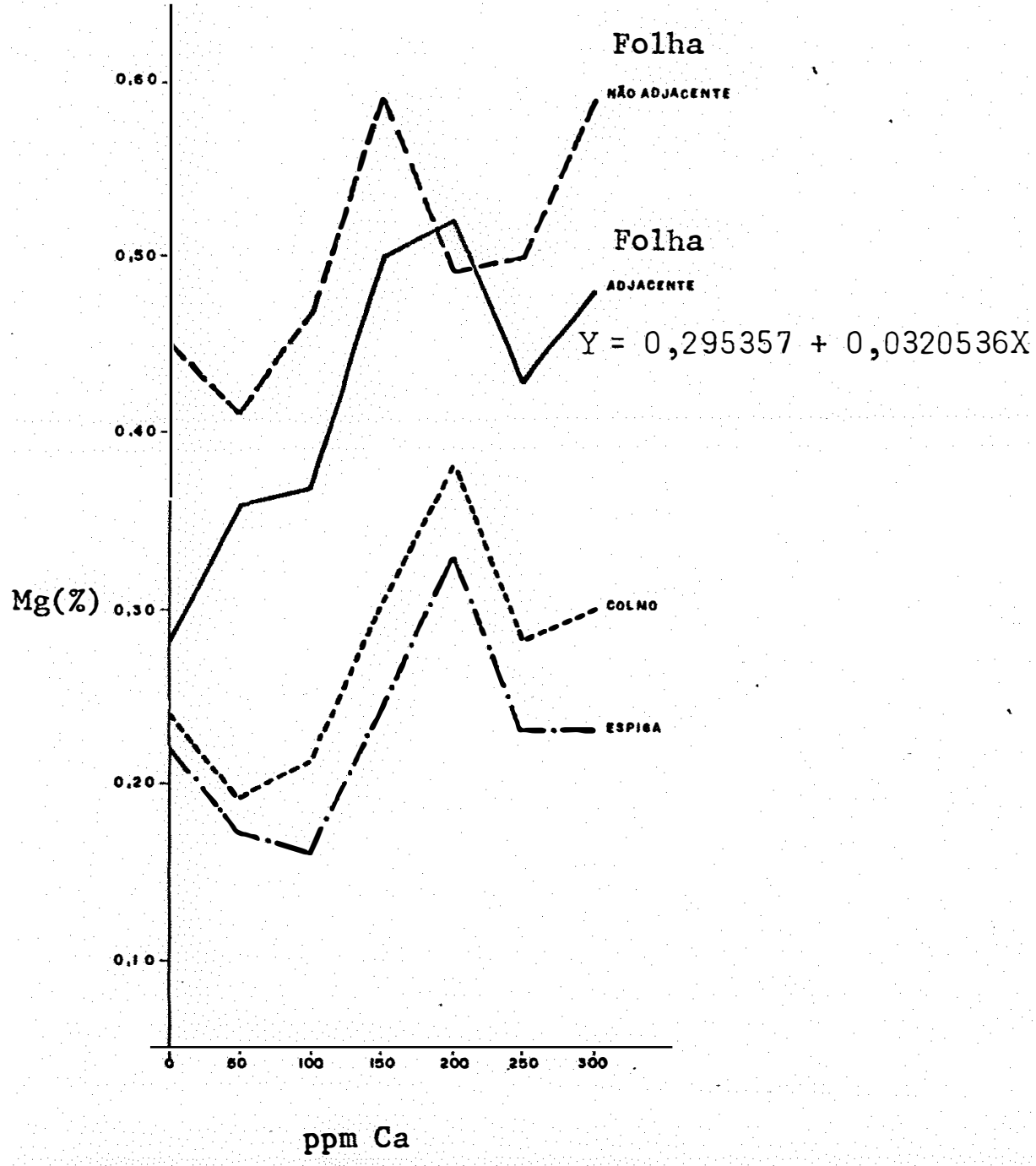

FIGURA 6. Teores de magnésio $(\%)$, determinados nas diferentes partes do milheto forrageiro, em função dos níveis de cálcio aplicados. 
e LAZARRAFF \& PITMAN (1966). São bastante escassas as informações sobre os efeitos diretos do aumento de cálcio na taxa de absorção de magnésio. Trabalhando com raízes de cevada, foi observada uma grande redução na absorção de magnésio na presença de cálcio segundo MOORE et alii (1961). Os teores médios de magnésio determinados nas diferentes partes do miIheto, estão assim distribuídos: folhas adjacentes - 0,41\%; folhas não adjacentes - 0,50\%; espigas - 0,20\% e nos colmos 0,27\%. Considerando-se o trabalho de FRANÇA et alii (1987), que determinaram valores de $0,48 \% ; 0,80 \% ; 0,35 \%$ e $0,79 \%$ de magnésio, para as mesmas partes da forrageira, com solução nutritiva completa, nos permite afirmar que os diferentes niveis de cálcio aplicados ao milheto forrageiro, deprimiram a absorção de magnésio.

A análise de regressão mostrou-se significatí va apenas para a interação dos tratamentos aplicados e a concentração do magnésio nas folhas adjacentes, conforme se observa através da equação descrita na Figura 6 .

Quanto às exigências nutricionais, a recomenda ção para novilhos é de 0,04 a 1,1\% na matéria seca da dieta e de $0,20 \%$, para vaca leiteira com $500 \mathrm{~kg}$ e uma produção inferior a $11 \mathrm{~kg}$ de leite por dia segundo NRC (1976 e 1978). Observa-se portanto, que os teores concentrados nas diferentes partes da forrageira, atendem satisfatoriamente às exigências nutricionais dos bovinos. 
4.2.6. BORO

Conforme se observa na Tabela 7 , os diferentes níveis de cálcio aplicados ao milheto forrageiro, foram signi ficativos para a acumulação de boro nas folhas adjacentes e nos colmos.

Verifica-se que houve uma variação do acūmulo de boro nas folhas adjacentes, da ordem de $152,7 \mu \mathrm{g}$, determinado no tratamento em que foi aplicado 250 ppm de cálcio, até 370,5 $\mathrm{gg}$ no nível de 150 ppm de cálcio.

Para as folhas não adjacentes, os tratamentos aplicados não influenciaram no acúmulo do boro, cuja oscilação foi de $690,5 \mu \mathrm{g}$, no tratamento testemunho, até 1,305,5 $\mu \mathrm{g}$, para o nível de 200 ppm de cálcio aplicado.

Nas espigas, o acúmulo de boro também não diferiu em função dos tratamentos aplicados, uma vez que, a variação foi de $489,0 \mu \mathrm{g}$, determinada para o tratamento com 100 ppm de cálcio, até $217,3 \mu \mathrm{g}$ de B, no tratamento testemunho.

Nos colmos, onde o acúmulo de boro foi significativa em função dos tratamentos aplicados, observouse uma variação de 953,7 $\mu \mathrm{g}$, com a aplicação de 200 ppm de cálcio, até 188,3 $\mathrm{\mu g}$ de B, determinado no tratamento testemunho.

Diversos estudos tem demonstrado que a adição de cálcio ao solo, reduz a disponibilidade de boro para as plantas segundo NAFTEL (1938), WEAT (1962) e GUPTA (1972). 


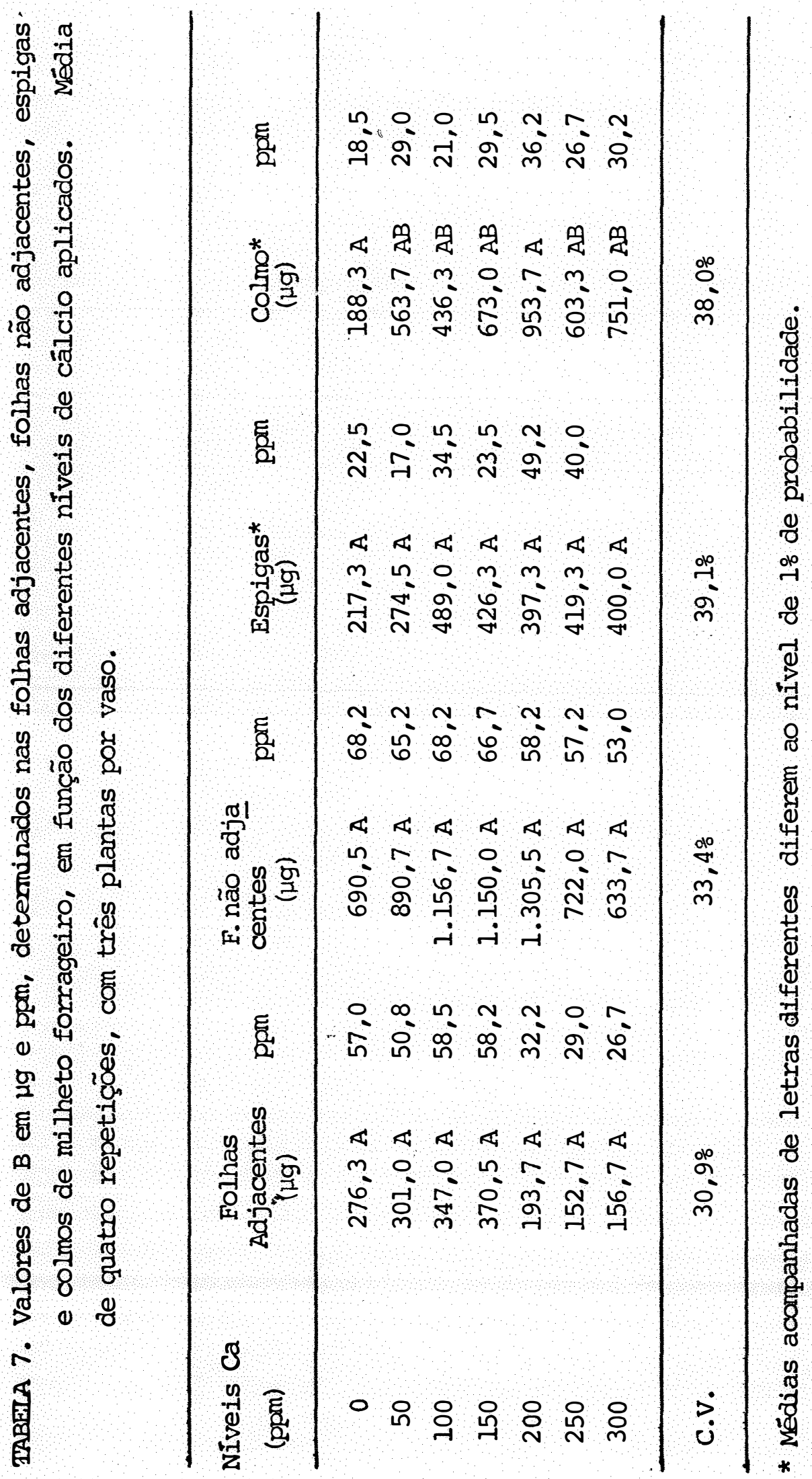


A disponibilidade e a absorção de boro pelas plantas nativas ou adaptadas é geralmente mais baixa em solos calcários, PETTERSON \& NEWMAN (1976). O nível de deficiência é de aproximadamente 15 ppm na matéria seca, enquanto toxidez ocorre, quando excede a $220 \mathrm{ppm}$ de boro, JONES (1972).

Níveis de 15 a $25 \mathrm{ppm}$ na maioria dos tecidos das folhas, de um modo geral, denotam deficiência, BRADFOR (1966), enquanto nos tecidos de plantas forrageiras, níveis de 6 a 9 ppm, não demonstraram sintomas de deficiência, GUPTA et alii (1971).

Os teores determinados neste trabalho, apresentaram uma variação de 26,7 a 58,5 ppm, nas folhas adjacentes; de 53,0 a 68,2 ppm, nas folhas não adjacentes; de 17,0 a 49,2 ppm, nas espigas e de 18,5 a 36,2 ppm. nos colmos. Estes teores são bastantes superiores aos diversos limites de deficiência acima citados, estando também, muito abaixo do limite da toxidez. Considerando-se ainda, o valor médio de $11,5 \mathrm{ppm}$, determinado em vinte e duas amostras do gênero Pennisetum por KAYONGO-MALLE (1975), verifica-se que, embora o cálcio e o boro sejam antagônicos, no presente trabalho, os diferentes tratamentos aplicados não deprimiram a absorção do boro.

A análise de regressão revelou significância para a interação dos tratamentos aplicados e a concentração de boro nas folhas adjacentes conforme se observa através da equação contida na Figura 7 . 
34.

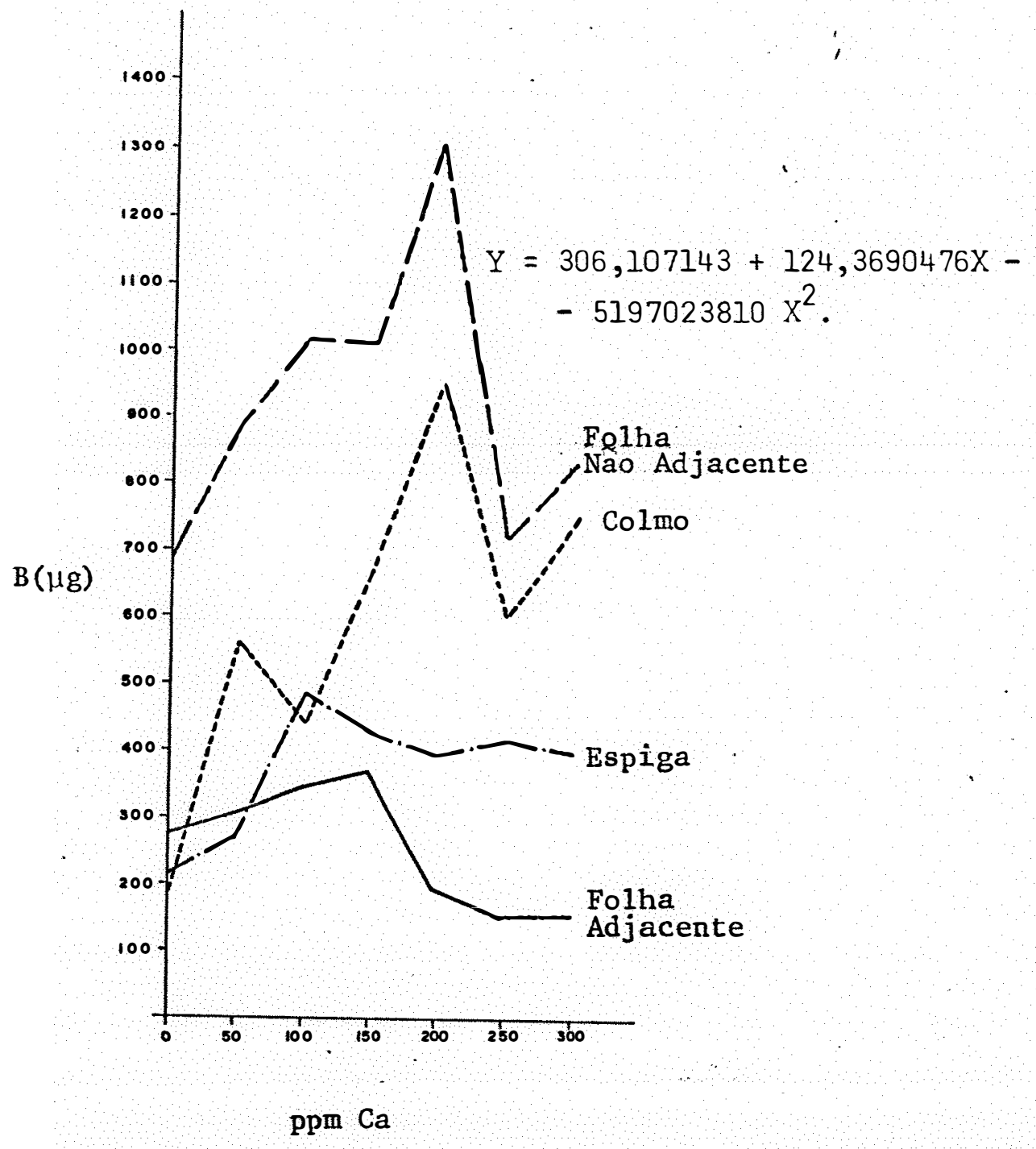

FIGURA 7. Teores de B $(\mu \mathrm{g})$ determinados nas diferentes partes do milheto forrageiro em função dos níveis de câlcio aplicados. 


\subsubsection{ZINCO}

A Tabela $8^{i}$, apresenta os valores de zinco concentrados nas diferentes partes do milheto forrageiro, os quais diferiram significativamente em função dos diferentes níveis de cálcio aplicados.

Os teores de zinco nas folhas adjacentes, apre sentaram uma variação de 371,0 $\mu \mathrm{g}$, com a aplicação de 150 ppm de cálcio, até 152,7 $\mu \mathrm{g}$ de zinco, para o tratamento com 200 ppm.

Nas folhas não adjacentes, ocorreu uma variação de 711,7 g, com a aplicação de 100 ppm de cálcio, até $340,6 \mu \mathrm{g}$ de zinco determinado no tratamento testemunho.

Para as espigas, observa-se uma variação de $1.254,6 \mu \mathrm{g}$, para o tratamento em que foi aplicado $150 \mathrm{ppm}$ de cálcio, até $480,14 \mu \mathrm{g}$ de zịnco, para o tratamento com o nível máximo de cálcio aplicado.

$$
\text { Nos colmos, verificou-se uma variação }
$$

de

$600,7 \mu \mathrm{g}$, para o tramento com 250 ppm de cálcio até $152,3 \mu \mathrm{g}$ de zinco para a aplicação de 50 ppm de cálcio:

A aplicação de $\mathrm{CaCO}_{3}$, reduziu a concentração de zinco em todas as partes das plantas, notadamente das foThas segundo PAULI et alii (1968). A deficiência de zinco ocorre em plantas crescidas numa larga variedade de solos, particularmente nos de $\mathrm{pH}$ elevados e em altas concentrações de cálcio (YOSHIDA, 1969 e SINGH, 1973). Os resultados obtidos neste trabalho, principalmente para as folhas e espigas, su- 


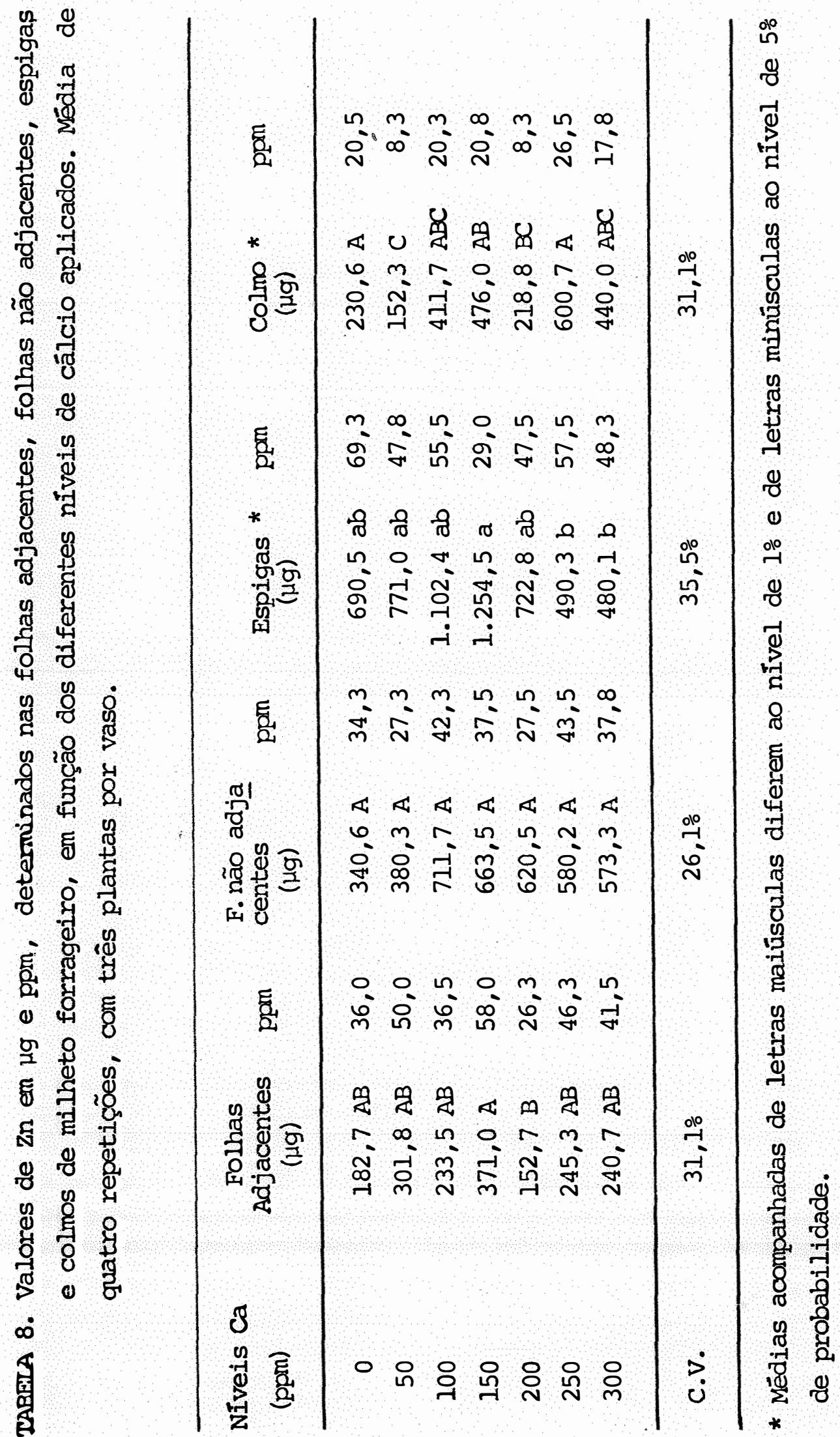




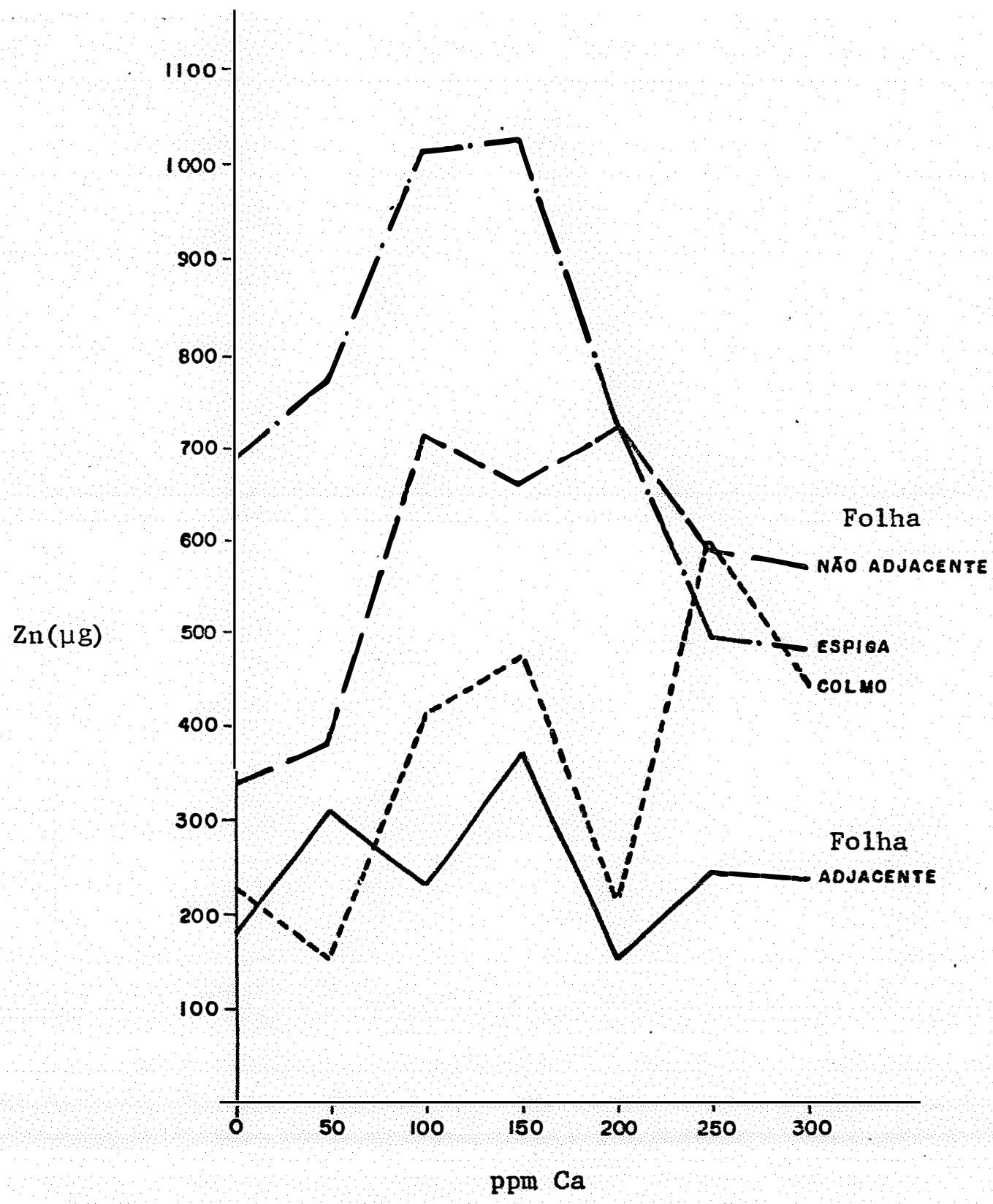

FIGURA 8. Teores de zinco ( $\mathrm{g})$, determinados nas diferentes partes do milheto forrageiro, em função dos níveis de cálcio aplicados. 
peram a média de $32,3 \mathrm{ppm}$, determinada para vinte e duas amos tras do gênero Pennisetum por KAYONGO-MALL (1975), exceto para os colmos, cuja média é bastante inferior, o que eviden cia a influência do cálcio na absorção do zinco, apenas neste órgão.

A análise de regressão não revelou significância entre os diferentes tratamentos aplicados ao milheto forrageito e a concentração do zinco na planta, conforme se observa na Figura 8.

Quanto à nutrição animal, recomenda-se de 20 a $30 \mathrm{ppm}$ de zinco para novilhos, NRC (1976) e de $40 \mathrm{ppm}$ na matéria seca da dieta, em se tratando de vacas leiteiras com $500 \mathrm{~kg}$, com produção de leite inferior a $11 \mathrm{~kg}$ por dia.

Verifica-se, portanto, que os teores de zinco determinados nas diferentes partes do milheto forrageiro, aten dem às exigências requeridas para os bovinos, principalmente em se tratando de novilhos. Exceção é feita para os colmos, cujo teor médio se encontra abaixo do limite mínimo da exigên cia nutricional.

\subsubsection{COBRE}

Os diferentes níveis de cálcio aplicados ao milheto forrageiro, influenciaram a concentração de cobre nas folhas adjacentes e não adjacentes, conforme se observa na Tabela 9. 


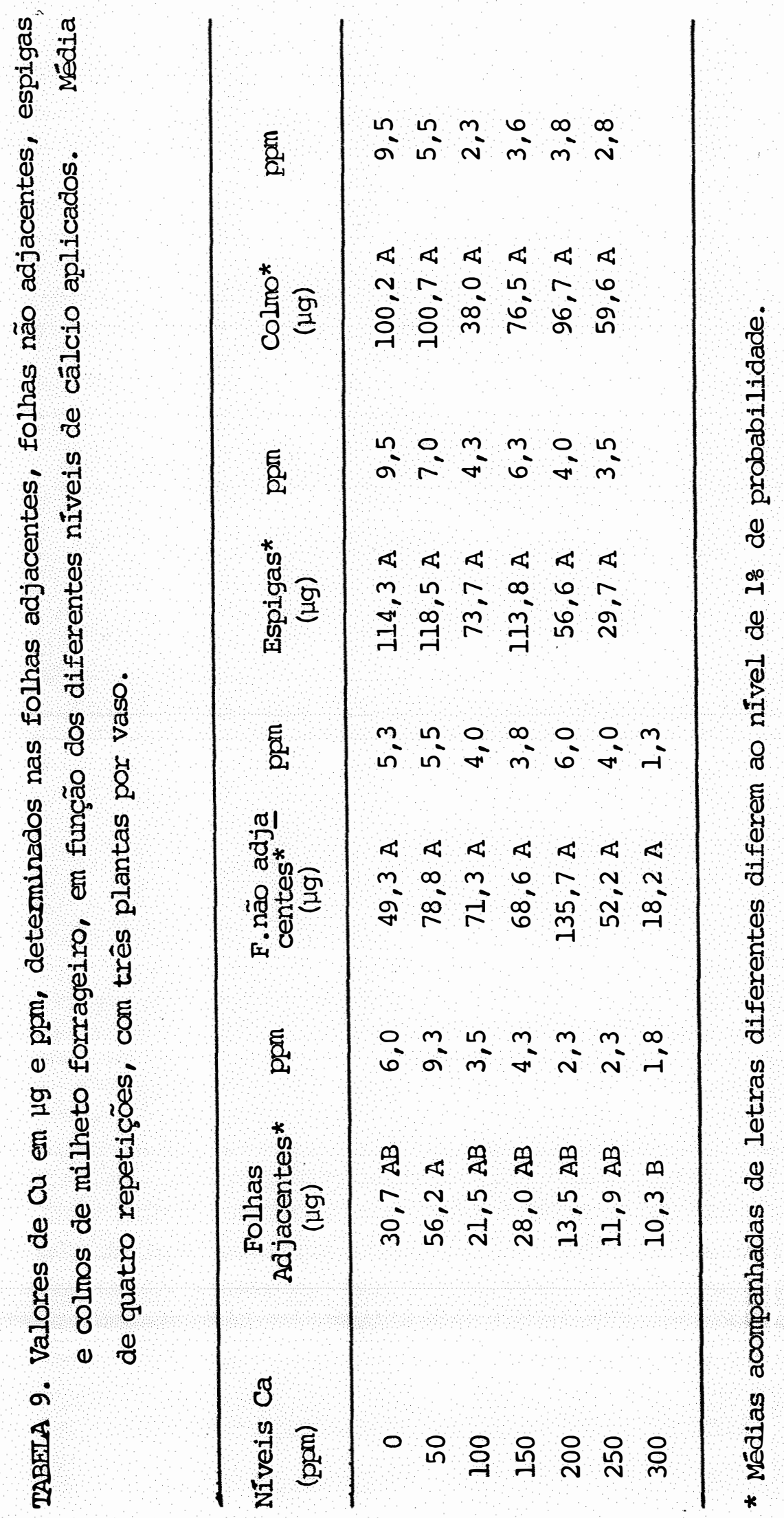


Os teores de cobre nas folhas adjacentes apresentaram uma variação de $56,6 \mu \mathrm{g}$, determinado no tratamento com a aplicação de $50 \mathrm{ppm}$ de cálcio, até 10,3 $\mathrm{\mu g}$ de $\mathrm{Cu}$, no tratamento com aplicação do nível máximo de cálcio. para as folhas não adjacentes verificou-se uma oscilação de 135,7 $\mu \mathrm{g}$, com a aplicação de 200 ppm de cálcio, até 18,2 ug de cobre pa ra o nível máximo de cálcio aplicado.

Para as espigas e os colmos, os tratamentos aplicados não revelaram significância, em relação à concentração do cobre.

Para as espigas, a variação observada foi de $118,5 \mu \mathrm{g}$, com a aplicação de 50 ppm de cálcio, até $29,7 \mu \mathrm{g}$ de cobre para o nível de $250 \mathrm{ppm}$. Nos colmos, ocorreu uma con centração de $100,7 \mu \mathrm{g}$, com a aplicação de 50 ppm de cálcio, até $38,0 \mu \mathrm{g}$ de cobre quando foi aplicado $100 \mathrm{ppm}$.

o efeito de calcário no abaixamento da concentração de cobre na solução do solo e na redução da absorção pelas plantas tem sido relatado por PEECH (1941) e LUCAS (1948). Outra pesquisa demonstrou que a calagem do solo, resultou numa mais baixa concentração de cobre nas plantas, segundo PATTERSON (1964). Teor médio de 27,1 ppm de cobre, foi determinado em vinte e duas amostras do gênero Pennisetum por KAYONGO-MALLE (1975). Um conteúdo de 6 ppm no tecido da forragem, indica que o elemento se encontra em quantidade suficiente, uma vez que, teores abaixo de 4 ppm, na maioria das plantas, já é inciicativo de deficiência segundo ANDREW \& THORNE (1962). 
41.

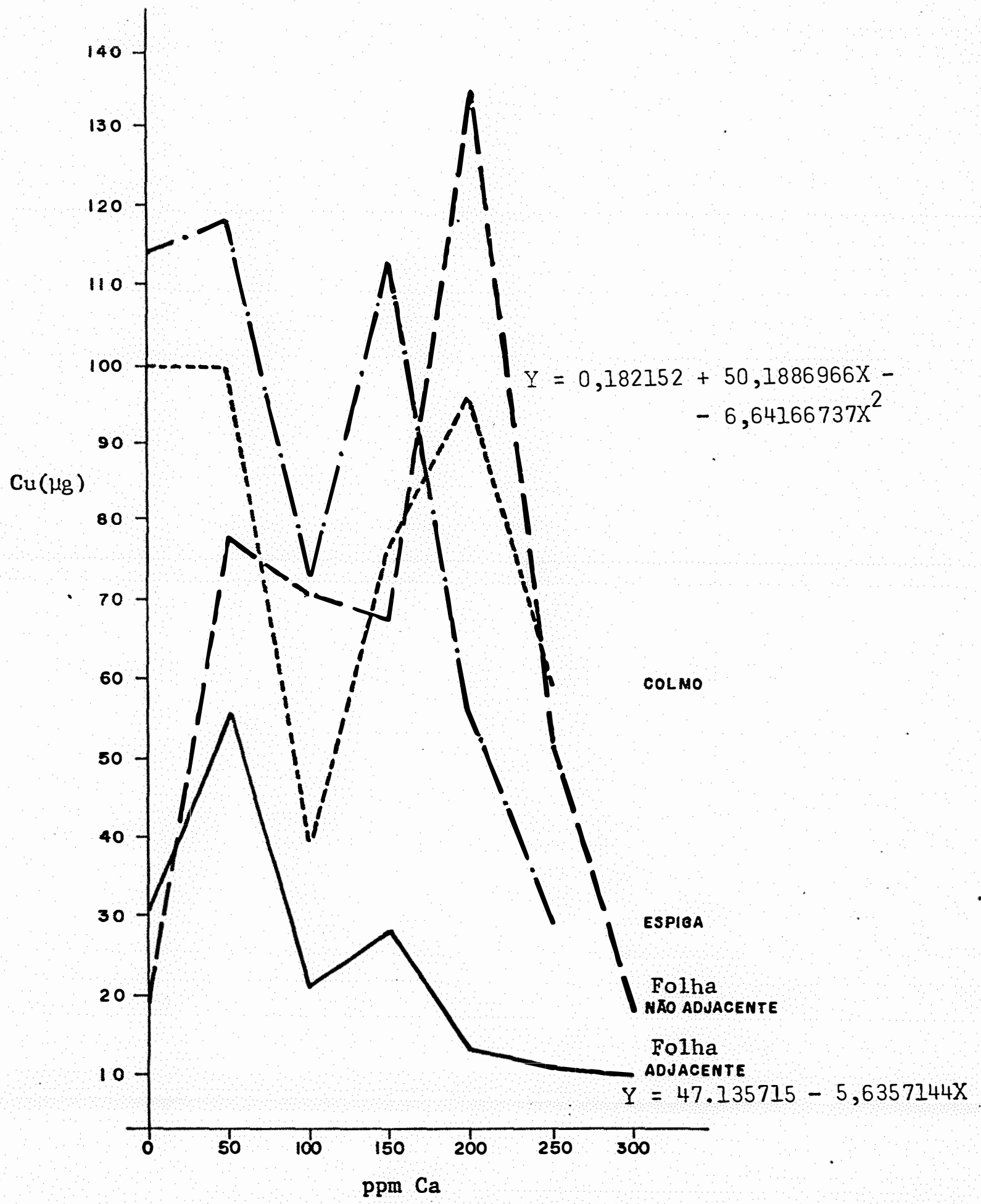

FIGURA 9. Teores de cobre $(\mu g)$, determinados nas diferentes partes do milheto forrageiro, em função dos níveis de cálcio aplicados. 
Os teores médios, determinados para as folhas e os colmos, se encontram, praticamente no limite de deficiên cia, até mesmo para as espigas, que mais se aproximaram do $\underline{1 i}$. mite de suficiência. Diante dos resultados obtidos, tornase evidente, que os tratamentos aplicados à forrageira, deprimiram a absorção do cobre.

A análise de regressão revelou significância para a interação dos tratamentos aplicados, sobre a concentra ção do cobre nas folhas adjacentes e não adjacentes, expresso através das equações descritas na Figura 9.

Do ponto de vista da nutrição animal, verifica-se que o teor médio das folhas adjacentes, folhas não adją centes, espigas e colmos, foi de $4,2 \mathrm{ppm} ; 4,2 \mathrm{ppm} ; 5,7 \mathrm{ppm}$ e 4,5 ppm de cobre, que muito embora tenham sido deprimidos pela aplicação dos diferentes níveis de cálcio, ainda assim aten dem às exigências nutricionais dos bovinos, que é de 4 ppm na matéria seca da:dieta, NRC (1976).

\subsubsection{FERRO}

Os diferentes tratamentos aplicados no milheto forrageiro, diferiram em relação à concentração de ferro nas diversas partes do milheto forrageiro, com exceção das folhas não adjacentes, conforme se observa na Tabela 10 .

Os teores de ferro determinados nas folhas adjacentes, apresentaram uma variação de $344,9 \mu \mathrm{g}$, no tratamento com a aplicação de $150 \mathrm{ppm}$ de cálcio, até $1.810,1 \mu \mathrm{g}$, no nível de 50 ppm de cálcio. 


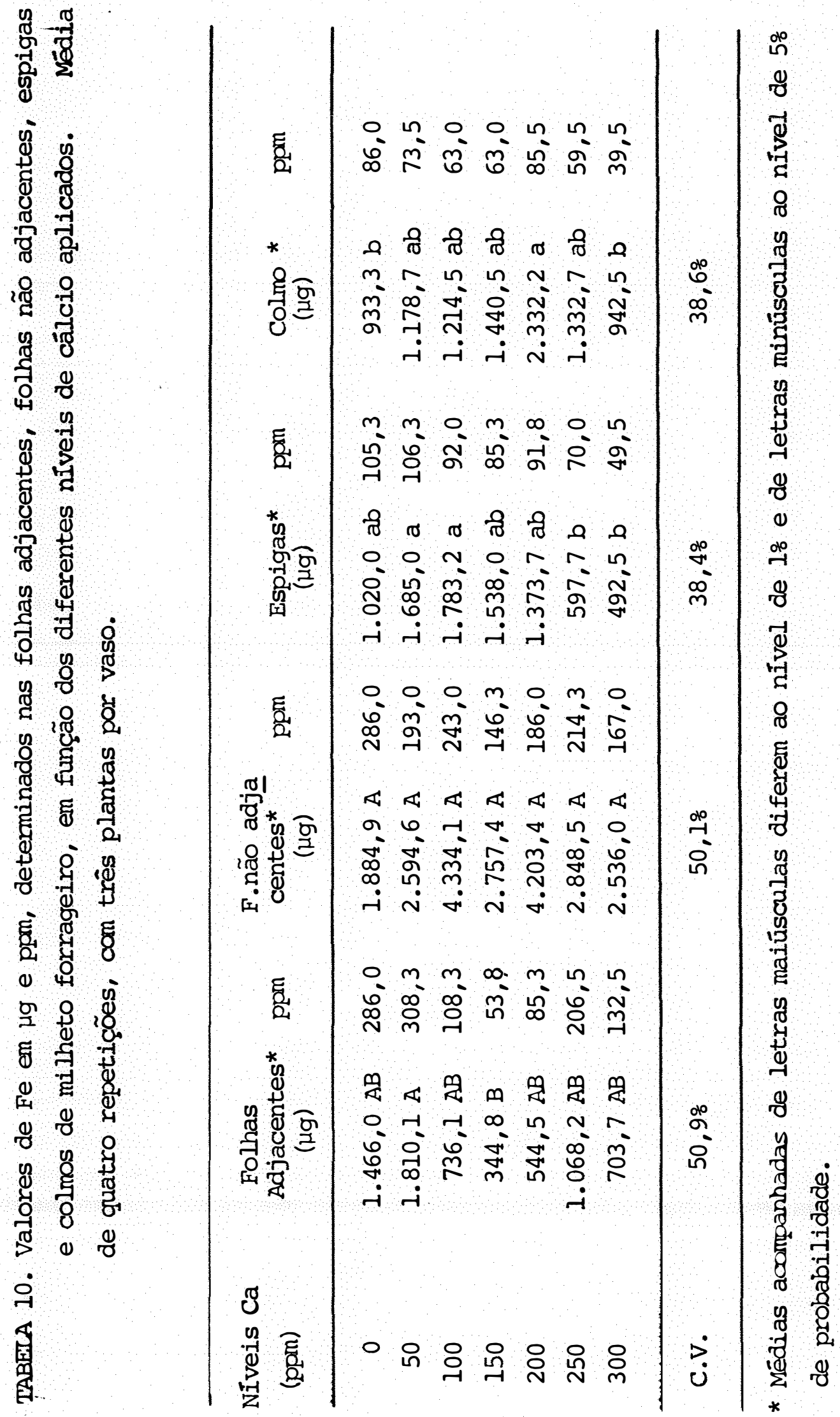


Nas folhas não adjacentes, cujas concentrações não foram influenciadas pelos diferentes níveis de cálcio, verificou-se uma variação de $4.334,1 \mu \mathrm{g}$ de ferro com a apli-

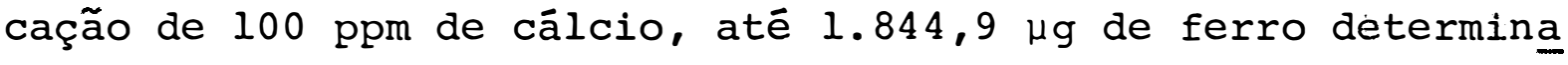
do no tratamento testemunho.

Para as espigas, a aplicação do mais alto nivel de cálcio proporcionou uma concentração de $492,5 \mu \mathrm{g}$ de ferro até $1.783,2 \mu \mathrm{g}$ de ferro para o tratamento com 100 ppm de cálcio.

Nos colmos, com a aplicação de 200 ppm de cálcio, determinou-se uma concentração de $2.332,2 \mu \mathrm{g}$ de ferro até 933,3 $\mathrm{\mu g}$ de ferro no tratamento testemunho.

o excesso de $\mathrm{CaCO}_{3}$ seguidamente reduz a absorção de ferro pelas plantas, em consequência de uma 'reduzida solubilidade do ferro na solução do solo segundo RUTLAND \& BUKOVAC (1971). Os teores médios de ferro determinados nas diferentes partes da forrageira, foram de 168,7 ppm, 205,1 ppm, 85,7 ppm e 67,1 ppm, nas folhas adjacentes, folhas não adjacentes, espigas e colmos.

Considerando-se o teor médio de $518 \mathrm{ppm}$ de fer ro determinado em vinte e duas amostras do gênero Pennisetum por KAYONGO-MALE (1975), torna-se evidente que os tratamentos aplicados ao milheto forrageiro, deprimiram a absorção do ferro.

A análise de regressão não revelou significância entre os tratamentos aplicados e a concentração de ferro nas diferentes partes da forrageira, de acordo com a Figura 10 . 
45.

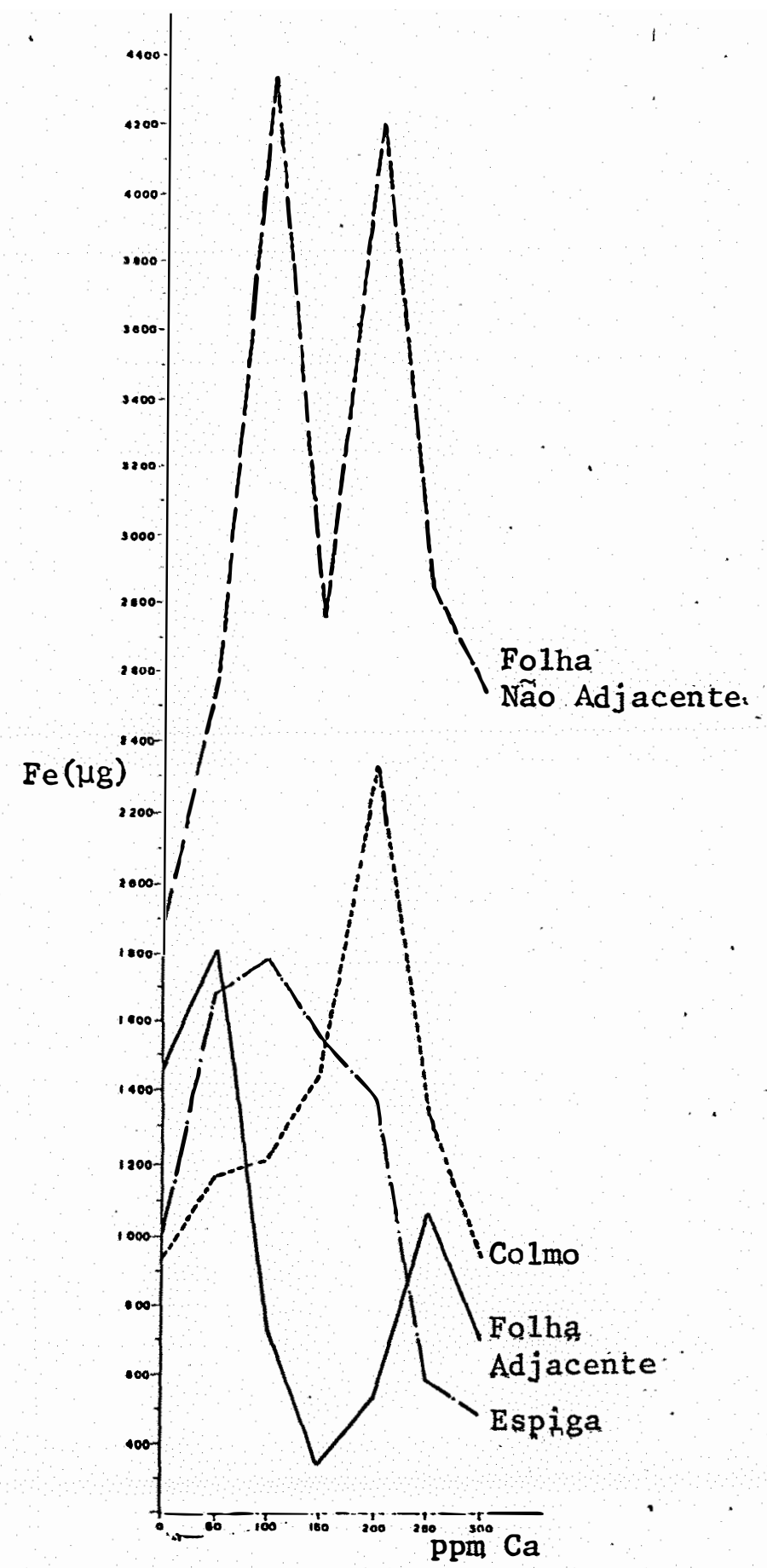

FIGURA 10. Teores de Ferro ( $\mu \mathrm{g})$, determinados nas diferentes partes do milheto forrageiro, em função dos níveis de cálcio aplicados. 
Quanto às exigências nutricionais dos bovinos, recomenda-se um teor de ferro de 10 ppm para novilhos e de 50 ppm na matéria seca da dieta, em se tratando de vaca com $500 \mathrm{~kg}$, com produção diāria inferior a $11 \mathrm{~kg}$ de leite, NRC (1976 e 1978).

\subsubsection{MANGANES}

Com exceção das espigas, os diferentes tratamentos aplicados ao milheto forrageiro, exerceram influência na absorção de manganês, nas diversas partes da forrageira, de acordo com a Tabela 11 .

Nas folhas adjacentes, verificou-se uma variação de 451,7 $\mu \mathrm{g}$ de manganês com a aplicação de 150 ppm de cál cio, até $237,5 \mu \mathrm{g}$ de manganês determinado no tratamento testemunho.

Nas folhas não adjacentes, o tratamento com

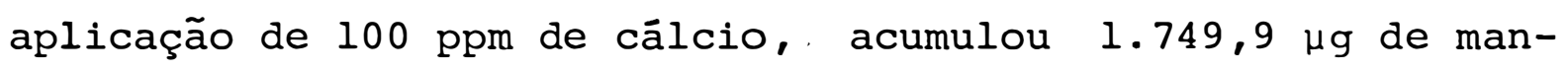
ganês que diferiu do tratamento testemunho, no qual foi determinado $539,3 \mu \mathrm{g}$ de manganês.

Nas espigas, o acúmulo manganês não dị feriu em relação aos tratamentos aplicados, ocorrendo uma va-

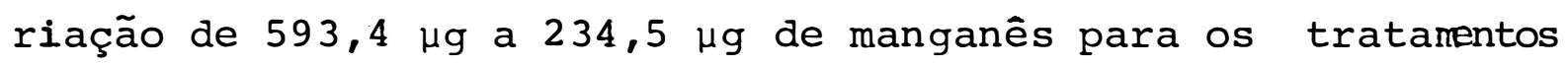
com aplicação de 150 e 300 ppm de cálcio, respectivamente.

$$
\text { Nos colmos, foi determinada uma acumulação }
$$

de 578,0 $\mathrm{\mu g}$ de manganês com a aplicação de 250 ppm de cálcio, que variou até $120,5 \mu \mathrm{g}$ de manganês no tratamento testemunho. 


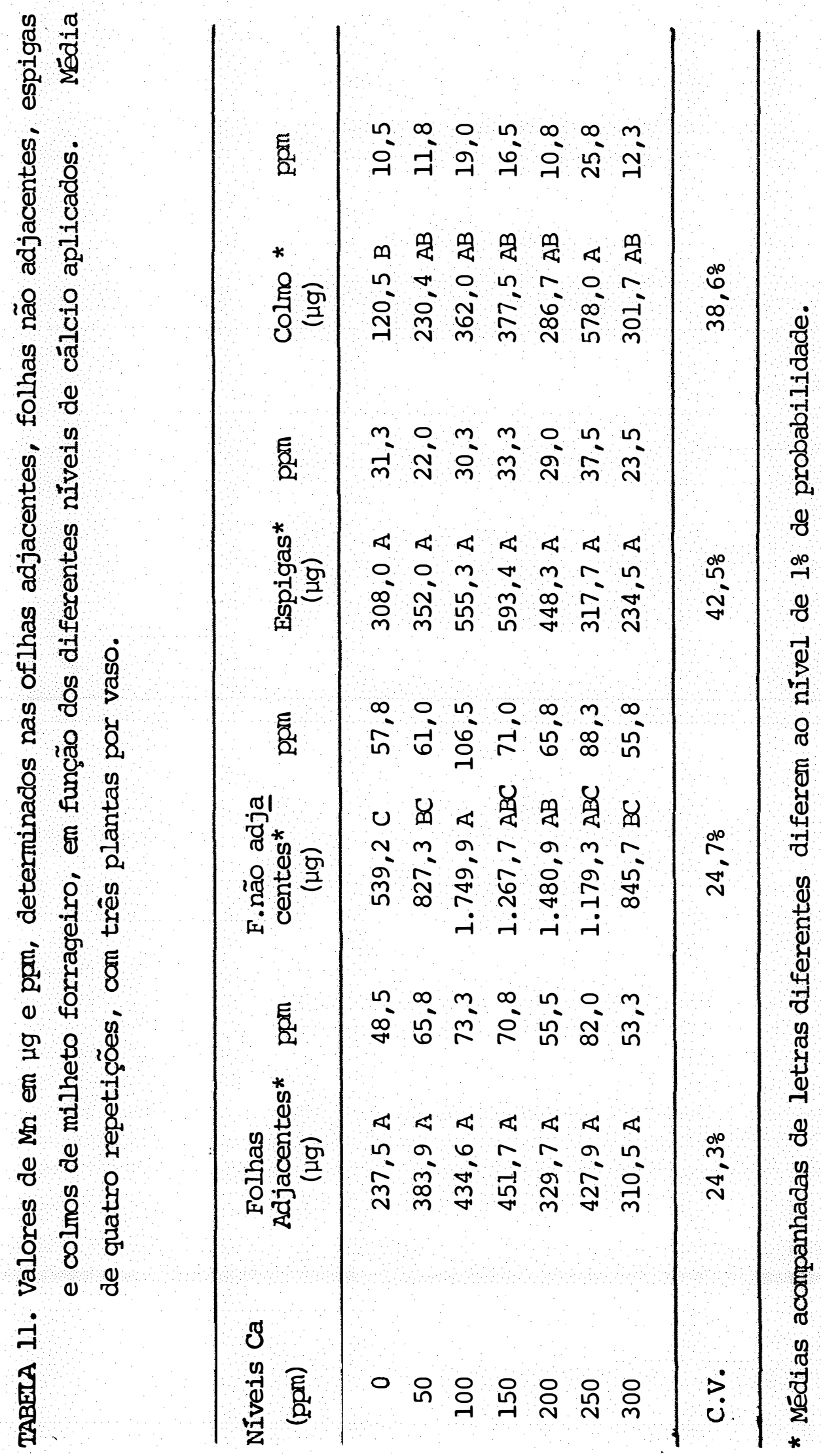


Neste trabalho, os teores determinados nas diversas partes da forragem superam o nivel crítico de deficiên cia de 44,6 e $12 \mu \mathrm{g}$, estabelecido por OHKI (1984) para as folhas e caules de trigo. Os valores médios concentrado em ppm nas diferentes partes do milheto forrageiro, foram da seguinte ordem: folhas adjacentes $=64,1 \mathrm{ppm}$; folhas não adjacentes $=72,3 \mathrm{ppm}$; espigas $=29,5 \mathrm{ppm}$ e colomos $=15,2 \mathrm{ppm}$. Observase portanto, que estes valores, de modo geral, se encontram numa faixa extremamente inferior, a média de 123 ppm, determi nada numa anşlise de vinte e duas amostras do gênero Pennisetum por KAYONGO-MALLE (1975). Verifica-se desta forma, que os tratamentos aplicados ao milheto forrageiro, exerceram influência na absorção do manganês.

A análise de regressão revelou significância em relação aos tratamentos aplicados e a concentração do elemento nas folhas adjacentes, não adjacentes e nas espigas. A Figura 11, com as respectivas equações, expressam as referidas interações.

Quanto à nutrição animal, os requerimentos de manganês necessārios para o crescimento do gado, via de regra, são menores do que para reprodução. Concentração de 10 ppm são consideradas adequadas para o crescimento, muito embo ra possa estar no limite para uma ótima performance. Segundo MCDOWELL et alii (1976) os requerimentos de manganês para a fertilidade máxima, excedem a 16 ppm. Recomendações entre 20 - 40 ppm são feitas pelo ARC (1965) e NRC (1970 e 1971). Os teores determinados neste trabalho, apresentaram uma variação 


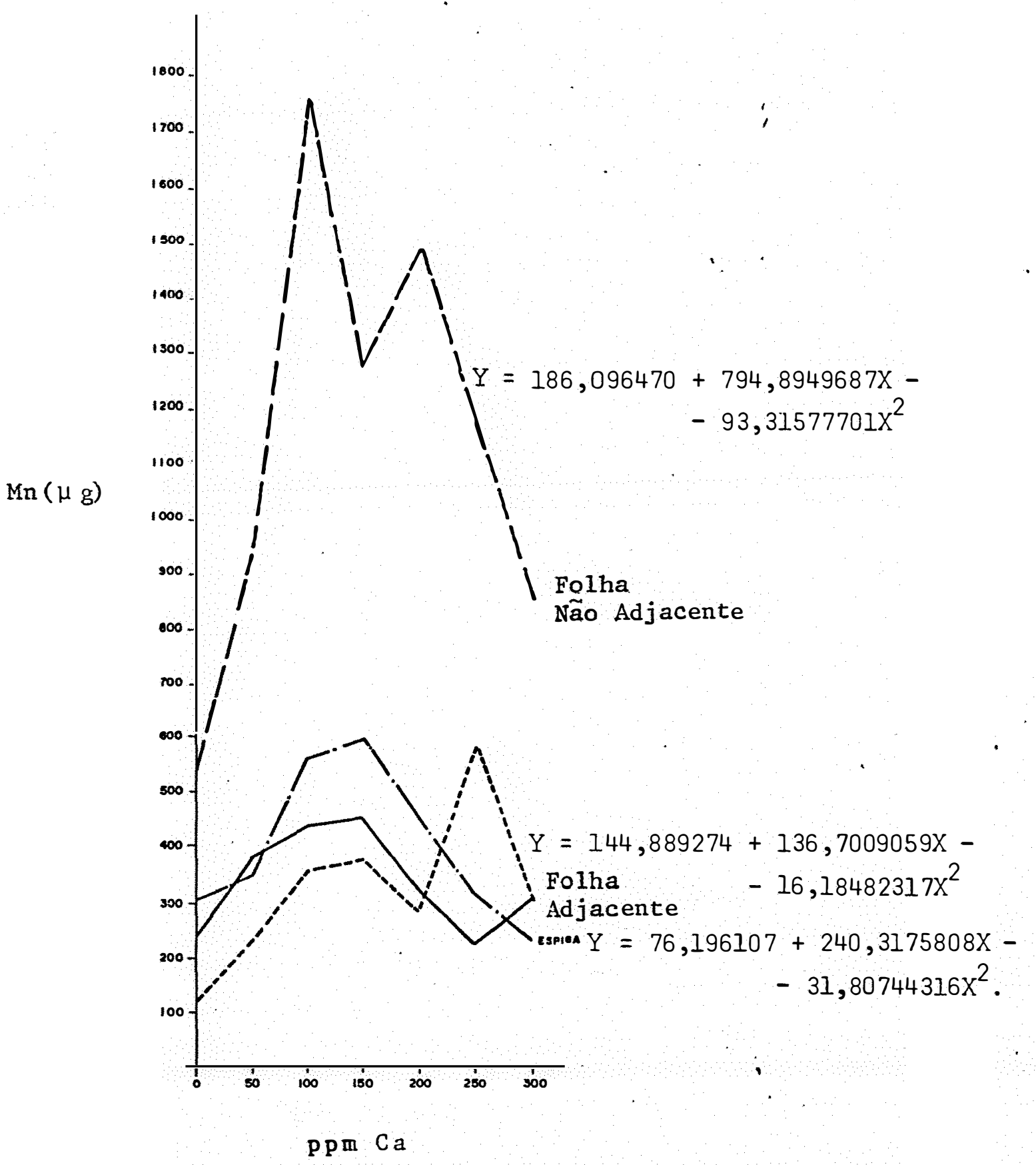

FIGURA 11. Teores de manganês $(\mu g)$, determinados nas diferentes partes do milheto forrageiro, em função dos ní veis de cálcio aplicados. 
de 10,5 ppm nos colmos, concentrado no tratamento testemunho dos colmos, até 106,5 ppm, nas folhas não adjacentes, com a aplicação de 100 ppm de cálcio. Portanto, esses teores atendem satisfatoriamente às exigências nutricionais dos bovinos. 


\section{CONCLUSÕES}

1) Diferentes níveis de cálcio na solução nutritiva correspondem a produção de matéria seca segundo uma equa ção do 2 o grau.

2) O nível de $200 \mathrm{ppm}$ de cálcio na solução nutrí tiva corresponde a produção máxima de matéria seca.

3) A aplicação dos níveis de cálcio ao milheto forrageiro deprime a absorção de N, P, K, Ca, Mg, Zn, Cu, Fe e Mn.

4) Os níveis de cálcio aplicados não inibe a absorção do boro.

5) Os níveis de cálcio na solução nutritiva não afetam os requerimentos mínimos dos elementos para a nutrição dos bovinos. 


\section{LITERATURA CITADA}

AMARASIRI, S.I. \& S.R. OLSEN, 1973. Liming as related to solubility of Pand plant growth in an acid tropical soil. Soil Sci. Soc. Am. Proc., 37: 716-21.

ANDREW, C.S. \& P.M. THORNE, 1962. Comparative responses to cooper of some tropical and temperature pasture legumes. Australian J. Agric. Research., 13: 821-835.

A.R.C., 1965. The nutrient requirements of ruminant livestock. Agricultural Research Council. Commonwealth Agricultural Bureaux.

A.R.C., 1980. The nutrient requirements of ruminant livestock. Agricultural Research Council, Commonwealth Agricultural Bureaux, 35lp.

BAILEY, A.V.; B. PICCOLO; G. SUMRELL \& G.W. BURTON, 1979. J. Agric. Food Chem., 27: 1421 .

BOGDAN, A.V. Tropical pasture and fodder plants; grasses and legumes. London, Longman, 475p., 1976.

BRADFORD, G.R., 1966. Boron. In: H.D. CHAPMAN (ed.), Diag nostic criteria for plants and soils. Univ. California, Riverside, pp.33-61. 
BURTON, G.W.; A.T. WALLACE \& K.O. RACHIE, 1972. Chemical com position and Nutritive Value of Pearl Millet ( Pennisetum typhoides (Burm.) Stapf and E.C. Hubbard) Graim.

CAIELLI, E.L.; L.M. BONILHA NETO; M. SANTA-MARIA \& H.J. SARTINI, 1979. Produção de matéria seca e valor nutritivo de pastos tropicais sob pastejo - I. Capim Gordura (Melinis minutiflora, Pal. de Beaux) mais Centrosema pubescens Benth Bol. Ind. Anim., Nova Odessa, 36(2):213-227.

CARVALHO, M.M.; C.S. ANDREW; D.G. EDWARDS \& C.J. ASHER, 1980. Comparative performance of six stylosanthes species in three acid soils. Aust. J. Agric. Res., 31: 61-76.

CASEY, P. \& K. LORENZ, 1977. Avaliação da qualidade de silagem de milheto comum (Pannisetum americanum L. (Leeke) com suplementação nitrogenadas ou energética. Rev. Soc. Bras. Zootec., 8 $(2): 316-331,1979$.

ELZAM, O.E. \& T.K. HODGES, 1967. Calcium inibition of potassium absorption in corn roots. Plant Physiol., 42: 1485-

EPSTEIN, E., 1961. The essential role of calcium in selective cation transport by plant cells. Plant Physiol., 36 : $437-444$.

FRANÇA, A.F.S.; H.P. HAAG \& Q.A.S. CARMELLO, 1987. Nutrição mineral de gramineas tropicais III. Deficiência de macronutrientes na produção de matéria seca e na composição mineral do milheto forrageiro. Anais da E.S.A. "Luiz de Queiroz", vol. XIIV (no prelo).

FRANKLIN, R.E., 1969. Effect of adsorbed cations on phosphorus uptake by excised roots. Plant Physiol., Lancaster $\underline{44}: 697-700$. 
GONZALES-ERICO, E., 1976. Effect of depth of lime incorporation on the growth of corn in Oxisols of Central Brazil. Tese de Doutoramento. Raleigh, North Carolina State University, $126 \mathrm{f}$.

GUPTA, U.C., 1972. Interaction effects of boron and lime on barley. Soil Sci., 106: 435-39.

GUPTA, U.C.; F.W. CALDER \& L.B. MacLEOD, 1971. Influence of added limestone and fertilizers upon the micronutrient con tent of forage tissue and soil. Plant and soil, 35: 249256 .

HESTER, J.B. \& F.A. SHELTON, 1936. The influence of certain replaceable bases in the soil upon the elemental composition vegeciale crops. Soil Sci., 42: 335-340.

HEWITT, E.J., 1952. A biological approach to the problems of soil acidity. Trans. $2^{\text {nd }}$ and $4^{\text {th }}$ Comm. Inst. Soc. Sci., Du blin, Vol. I, pp.107-18.

HIATT, A.J., 1970. An anomaly in potassium accumulation by barley roots. Plant Physiol., 45: 411-414.

HOLFORD, I.C.R., 1985. Effects of lime on yields and phospha te uptake by clover in relation to changes in soil phospha te and related characteristics. Aust. J. Soil Res., 23: 76-83.

HOOYMANS, J.J.M., 1964. The role of calcium in the absorp tion of anions and cations by excised barley roots. Acta Bot. Neerl. 13: 507-540.

JACOBSON, L.; R.J. HANNAPEL; D.P. MOORE \& M. SCHAEDLE, 1961. Influence of $\mathrm{Ca}$ on selectivity of ion absorption process. plant Physiol., 36: 58-61. 
JONES, J.B. Jr., 1972. Plant tissue analysis for micronutrients. p.319-34l. In: J.J. Mortevelt (ed) Micronutrient in agriculture soil. Soc. Am. Madison.

JONES, R.G.W. \& O.R. LUNT, 1967. The function of calcium in plants. Bot. Rev. , 33: 407-426.

KAHN, J.S. \& J.B. HANSON, 1957. The effect of calcium on potassium accumulation in corn and soybean roots. Plant Phy siol., 32: 312-316.

KAYONGO-MALLE, H., 1975. Mineral composition of some tropical grasses and their relationships to the organic constituints and estimates of digestibility. E.A. Agric. For. J., 40 (4): 428-38.

LAZARAFF, N. \& M.G. PITMAN, 1966. Calcium and magnesium uptake barley seedlings. Aust. J. Biol. Sci., 19: 991-1005.

LEGGETT, J.E., R.A. GALLOWAY \& M.G. GAUCH., 1965. Calcium acti vation of orthophosphate absorption by barley roots. plant Physiol., Lancaster, 40 : 897-902.

LOPES, A.S., 1983. Solos sob "Cerrado". Características, pro priedades e manejo. Piracicaba, Instituto da potassa \& Fosfato e Instituto Internacional da Potassa. 162p.

LUCAS, R.E., 1948. Chemical and physical behavior of cropper in organic soils. Soil sci., 66: 119-129.

MAAS, E.V. \& G. OGATA, 1971. Absorption of magnesium chloride by excised corn roots. Plant physiol., 47: 357-360.

MALAVOLTA, E., 1976. Manual de química agrícola. Nutrição de plantas e fertilidade do solo. São paulo, Edit. Agronômica Ceres. 606p. 
MALAVOLTA, E.; J.P. DANTAS; R.S. MORAIS \& F.P. NOGUEIRA, 1979. Calcium problems in Latin American. Commun. Soil Sci. Pl. Anal., 10: 29-40.

MASCARENHAS, H.A.A., 1977. Cálcio, enxofre e ferro em solo e na planta. Fundação Cargill, llp.

MCDOWELL, L.R.; R.H. HOUSER, K.R. FICK \& M.O. MENDES, 1976. O ferro, o manganês e o zinco na nutrição de ruminantes. In: Simpósio Latino-Americano sobre pesquisa em nutrição mineral de ruminantes em pastagens. 22 a 26 de março, B.H. MG - Brasil.

MENGEL, K. \& E.A. KIRKBY, 1982. Principles of plant nutrition. International Potash Institute - Bern/Switzerland.

MILFORD, R. \& D.J. MINSON, 1965. Intake of tropical pasture species. Proceedings of the $9^{\text {th }}$ International Grassland Congress, São Paulo, 815-822.

MOORE, D.P., R. OVERSTREET \& L. JACOBSEN, 19.61. Uptake of magnesium and its interaction with calcium in excised barley roots. Plant Physiol., 36: 290-295.

NAFTEL, J.A., 19.38. Recent studies on boron in soils. Soil Sci. Soc. Am. Proc., 106: 435-439.

N.R.C., 1976. Nutrient requeriment of domestic animals. No 4. Nutrient requeriment of beef catle. 5th ed. National Academy of Sciences, Washington, D.C.

N.R.C., 1978. Nutrient requeriments of dairy cattle, 5. ed. revisada, 1978. National Research Council, National Academy of Sciences, Washington, D.C. 76p. 
NWACHUKI, N.I.C., 1968. Effects of temperatura and dinitrophenol on the uptake of potassium and sodium ions on Ricinus communis roots. Plant Physiol., 83:150-60.

OHKI, K., 1984. Manganese deficiency and toxicity effects on growth, development, and nutrient composition in wheat. Agron. Journal, 76:213-218.

PAULI, A.W.; ROSCOE ELLIS JR. \& H.C. MOSER, 1968. Zinc uptake and translocation as influenced by phosphorus, and calcium carbonete. Agr. Journal, 60:394-96.

PAVAN, M.A., 1983. O cálcio como nutriente para as culturas. In: Anais do Seminārio $\mathrm{P}, \mathrm{Ca}, \mathrm{Mg}, \mathrm{S}$ e micronutrientes. Situação atual e perspectiva na agricultura. São Paulo, Manah $\mathrm{S} / \mathrm{A}, 144 \mathrm{p}$.

PEECH, M., 1941. Availability of ions in light sandy soils as affected by soil reactions: Soil Sci., 51:473-486.

PETTERSON, L.A. \& R.C. NEWMAN, 1976. Influences of soil pH on the availability of added boron. Soil Sci. Soc. Am. J. $\underline{40}: 280-282$.

RAINS, D.W.; W.E. SCHMID \& E. EPSTEIN, 1964. Absorption of cations by roots. Effect of hydrogen ions and essential role of calcium. Plant Physiol., 39:274-278.

ROBSON, A.S.; D.G. EDWARDS \& J.F. LONERAGAN, 1970. Calcium stimulation of phosphate absorption by annual legumes. Aust. J. Agric. Res., 21:601-12. 
RUTLAND, R.B. \& M.J. BUKOVAC, 1971. The effect of calcium bicarbonate on iron absorption and distribution by chrysan themum morifolium (RAM). Plant and Soil, 35: 225-236.

SARRUGE, J.R., 1975. Soluções nutritivas. Summa Phytopathologica, 1: 231-233.

SARRUGE, J.R. \& HAAG, H.P., 1974. Anālises químicas em plantas. E.S.A. "Luiz de Queiroz", USP, Piracicaba, 56p.

SCHMEHL, W.R., M. PEECH \& R. BRADFIELD, 1950. Causes of poor growth of plants on acid soils and beneficial effects of liming. I. Evaluation of factors responsible for acid soil injury. Soil Sci., 70: 393-410.

SINGH, B.R. \& SINGH, M., 1973. Studies on the supply of zinc to rice seedlings in Khaira affected lands. Indian $\mathrm{J}$. Agric. Sci.

SMITH, D.T. \& N.A. CLARK, 1968. Effect of soil nutrient and $\mathrm{pH}$ on nitrate and growth of Pearl millet (Pennisetum typhoides (Burm.)). Agron. J., 60: 38-40.

TANADA, T., 1955. Effect of ultraviolet radiation and calcium and their interaction on salt absorption by excised mung bean roots. Plant Physiol., Lancaster, 30: 221-5.

VIEIRA, L.S., 1975. Manual da ciência do solo. são Paulo, Edit. Agr. Ceres Ltda., $464 \mathrm{p}$.

WAISEL, Y., 1962. The effect of $\mathrm{Ca}$ on the uptake of monovalent ions by excesed barley roots. Plant Physiol., 15 : 709-724. 
WEAT, J.I. \& I. PETTERSON, 1962. Effect of soil pH and textu re on the availability of water soluble born in the soil. Soil Sci. Soc. Am. Proc., 26: 344-46.

WHITE, R.E. \& A.W. TAYLOR, 1977. Effect of $\mathrm{pH}$ on phosphate adsorption and isotopic exchange in acid soils at low and high additiones of soluble phosphate. J. Soil Sci., 28: 48-61.

YOSHIDA, S. \& TANAKA, A., 1974. Zinc deficiency of rice plants in calcareous soils. Soil Sci and Plant Nutrition, 15: 76-80 . 